\title{
Ligand-mediated cytoplasmic retention of the Ah receptor inhibits macrophage-mediated acute inflammatory responses
}

\author{
Gulsum E Muku1,4, Tejas S Lahoti ${ }^{1,4}$, lain A Murray ${ }^{1}$, Michael A Podolsky ${ }^{1}$, Kayla J Smith¹, Troy D Hubbard', Guray Kuzu², \\ Krishne Gowda ${ }^{3}$, Shantu G Amin ${ }^{3}$ and Gary H Perdew ${ }^{1}$
}

The Ah receptor (AHR) has been shown to exhibit both inflammatory and anti-inflammatory activity in a context-specific manner. In vivo macrophage-driven acute inflammation models were utilized here to test whether the selective Ah receptor modulator 1-allyl-7-trifluoromethyl-1H-indazol-3-yl]-4-methoxyphenol (SGA360) would reduce inflammation. Exposure to SGA360 was capable of significantly inhibiting lipopolysaccharide (LPS)-mediated endotoxic shock in a mouse model, both in terms of lethality and attenuating inflammatory signaling in tissues. Topical exposure to SGA360 was also able to mitigate joint edema in a monosodium urate (MSU) crystal gout mouse model. Inhibition was dependent on the expression of the high-affinity allelic AHR variant in both acute inflammation models. Upon peritoneal MSU crystal exposure SGA360 pretreatment inhibited neutrophil and macrophage migration into the peritoneum. RNA-seq analysis revealed that SGA360 attenuated the expression of numerous inflammatory genes and genes known to be directly regulated by AHR in thioglycolate-elicited primary peritoneal macrophages treated with LPS. In addition, expression of the high-affinity allelic AHR variant in cultured macrophages was necessary for SGA360-mediated repression of inflammatory gene expression. Mechanistic studies revealed that SGA360 failed to induce nuclear translocation of the AHR and actually enhanced cytoplasmic localization. LPS treatment of macrophages enhanced the occupancy of the AHR and p65 to the Ptgs2 promoter, whereas SGA360 attenuated occupancy. AHR ligand activity was detected in peritoneal exudates isolated from MSU-treated mice, thus suggesting that the anti-inflammatory activity of SGA360 is mediated at least in part through AHR antagonism of endogenous agonist activity. These results underscore an important role of the AHR in participating in acute inflammatory signaling and warrants further investigations into possible clinical applications.

Laboratory Investigation (2017) 97, 1471-1487; doi:10.1038/labinvest.2017.92; published online 11 September 2017

Resident and invading macrophages are important early mediators of many acute inflammatory conditions. For example, gout is a clinically relevant disease where resident macrophages have a central role in the initial inflammatory response to monosodium urate (MSU) crystals. ${ }^{1,2}$ Gout is most often defined in terms of elevated uric acid levels, a metabolite of purine degradation, which leads to crystal formation within articular joints. Multiple mechanisms of MSU crystal recognition has been described, including engagement by the complement system, immunoglobulins, and lipid sorting. ${ }^{3}$ The early phase of the disease is characterized by an elevation in cytokines such as IL1B, TNFA, and invasion of neutrophils. ${ }^{4}$ In particular, IL1B signaling through the IL1R and MyD88 has been shown to have a central role in disease pathogenesis. ${ }^{5}$ Clinical studies utilizing IL1B inhibitors have shown significant efficacy in preventing gout reoccurrence, ${ }^{6}$ demonstrating that attenuation of innate inflammatory signaling in gout patients can be an effective treatment strategy.

Endotoxin (LPS) induces acute inflammation and is often used as a mouse model to study the acute inflammatory aspects of septic shock. This condition is clinically defined as a systemic infection that results in an acute innate immune response, which if unresolved ultimately leads to hypotension, organ dysfunction, and death. ${ }^{7}$ Sepsis has a mortality rate ranging from 15 to $30 \%$ in hospitals, and is the eleventh

\footnotetext{
Department of Veterinary and Biomedical Sciences and The Center for Molecular Toxicology and Carcinogenesis, The Pennsylvania State University, University Park, PA USA; ${ }^{2}$ Department of Biochemistry and Molecular Biology, Center for Eukaryotic Gene Regulation, The Pennsylvania State University, University Park, PA, USA and ${ }^{3}$ Department of Pharmacology, Pennsylvania State College of Medicine, Hershey, PA, USA

Correspondence: Dr GH Perdew, PhD, The Center for Molecular Toxicology and Carcinogenesis, 309 LSB, The Pennsylvania State University, University Park 16802, PA, USA. E-mail: ghp2@psu.edu

${ }^{4}$ These authors contributed equally to this work.

Received 7 May 2017; revised 12 July 2017; accepted 18 July 2017
} 
leading cause of death in the U.S. ${ }^{8}$ With an aging population, the incidence of sepsis is expected to increase and thus is a major health care cost factor. Despite a greater understanding of the various mechanisms of septic shock that can lead to death, there has been limited progress in developing therapies that can attenuate a range of adverse effects and work in combination with antibiotics. There is extensive literature demonstrating that levels of cytokines and endotoxemia inversely correlate with survival. ${ }^{9}$ However, in the past 30 years numerous human clinical trials targeting cytokines have failed to significantly improve clinical outcomes. Owing to the complexities of the various responses to bacteria, an approach that targets multiple pathways may yield new avenues for effective treatment in humans. Aryl hydrocarbon receptor (AHR) knockout mice have been shown to be highly sensitive to LPS-mediated shock with lethality as the endpoint. ${ }^{10}$ Furthermore, treatment of mice with an AHR agonist results in enhanced survivability in wild-type mice.

The AHR is a ligand-activated member of the bHLH-PAS family of transcription factors. This receptor was originally identified as the primary mediator of 2,3,7,8-tetrachlorodibenzo-p-dioxin (TCDD) toxicity. ${ }^{11,12}$ The potent toxicity of TCDD is attributed to its long half-life in vivo and its ability to hyper-activate the AHR. The AHR exists in the unliganded state in a core tetrameric complex with a dimer of hsp90 and $\mathrm{X}$-associated protein 2 and this complex can undergo nucleocytoplasmic shuttling. ${ }^{13,14}$ Upon binding an agonist, the AHR translocates into the nucleus, where hsp90 dissociates along with heterodimerization of the AHR with the Ah receptor nuclear translocator (ARNT). AHR/ARNT complex is capable of modulating gene transcription through interaction with dioxin-responsive elements (DRE). The AHR has also been shown to heterodimerize with Rel B and bind to a unique response element. ${ }^{15}$ Furthermore, the AHR can alter transcriptional activity through interacting with retinoblastoma protein, E2F, and the estrogen receptor in the nucleus. ${ }^{16-18}$ The AHR has been extensively studied in terms of its role as a xenobiotic sensor that regulates the expression of a number of important enzymes involved in phase I and II metabolism. More recently, physiological role of the AHR has started to emerge in part through the use of Ahr null mice, including a role in liver and vascular development, reproductive success, epithelial barrier function, and innate and adaptive immunity. ${ }^{19,20}$ Because of the number of developmental issues observed in these mice, other mouse models have been found to be useful. For example, the use $A h^{b}$ and $A h^{d}$ congenic mice that express a high- and low-affinity AHR that exhibit a 10-fold difference in affinity for TCDD have been used to study the effect of AHR activation. ${ }^{21,22}$ The function of the AHR in immune function is currently an area of intense interest. For example, treatment of MCF-7 cells with IL1B and TCDD revealed a synergistic induction of IL6, which occurred at the level of enhanced transcription. ${ }^{23}$ The AHR occupied the enhancer region of the IL6 promoter and facilitated p65 acetylation, thus suggesting an important function of the AHR in innate immune signaling. The AHR is also involved in innate T-cell immunity as a key transcription factor modulating T-cell differentiation..$^{24,25}$

The AHR can bind a wide range of xenobiotics (eg, planar polycyclic aromatic hydrocarbons, $\mathrm{PCBs}$ ), bacterial products (eg, indole, 1-hydroxyphenazine), dietary (eg, indole-3carbinol products), and endogenous compounds (eg, indoxyl sulfate, bilirubin). ${ }^{26-30}$ The endogenously produced tryptophan metabolite kynurenine has been shown to activate the AHR leading to adaptive immune tolerance. ${ }^{31}$ However, the key AHR ligands that mediate its physiologic activity remain unclear. A number of AHR antagonists have been developed that are useful in characterizing the role of the AHR in various cellular processes. ${ }^{32,33}$ For example, a human AHR antagonist was developed, which promotes expansion of hematopoietic stem cells. ${ }^{34} \mathrm{~A}$ third distinct class of AHR ligands has been characterized that fails to induce heterodimerization with ARNT, yet exhibits significant antiinflammatory activity. ${ }^{35,36}$ These compounds are able to repress acute-phase gene expression in liver cell lines and reduce edema in a TPA ear edema assay. ${ }^{37}$ Through a structure-activity approach, a compound termed SGA360 was developed that efficiently attenuated inflammatory signaling in the assays examined. These compounds were termed Selective Ah receptor modulators (SAhRM) and are distinct from antagonists, which appear to inhibit both agonist and selective ligand activity. ${ }^{32}$ The cellular targets modulated by the anti-inflammatory activity of SAhRMs have not been established.

Studies in an endotoxin shock model have demonstrated that ARNT is dispensable for AHR agonist-mediated attenuation of inflammatory response, indicating that DREmediated transcription is not a prerequisite to confer the AHR-dependent protective effect. ${ }^{10}$ Thus, considering the rationale that SGA360 focuses AHR activity into a non-DRE mode of action, which has previously been shown to be antiinflammatory, we have examined the effect of the SAhRM SGA360 upon LPS treatment. Data presented here reveals that SGA360 has the capacity to significantly attenuate LPSinduced septic shock and MSU crystal-mediated joint edema. The effect of SGA360 correlated with AHR ligand binding affinity as assessed using $A h^{b}$ and $A h^{d}$ congenic mice. Through examination of inflammatory signaling after LPS exposure in macrophages we identified that inhibition of AHR transcriptional activity in combination with attenuation of NF-KB signaling is the likely mechanism of SAhRM/AHRmediated suppression of LPS lethality and inflammatory signaling. Furthermore, mechanistic studies indicated that the activity of SGA360 is mediated at least in part through inhibition of AHR nuclear activity.

\section{MATERIALS AND METHODS Reagents}

LPS (E. coli 0111:B4 was obtained from Santa Cruz Biotechnology, Santa Cruz, CA, USA). MSU crystals were 
prepared as described. ${ }^{1}$ The following anti-murine antibodies were used for flow cytometric analysis: anti-F4/80 (BM8, Biolegend), anti-Ly6G (1A8, Biolegend), anti-CD11b (M1/70, Biolegend), anti-CD45 (30-F11, Ebioscience), and anti-Ly6C (AL-21, BD Biosciences). Dead cell exclusion was conducted using Live/Dead Fixable Red Dead Cell Stain Kit (Invitrogen, Carlsbad, CA, USA). The plasmid pG-ARNT 325, which expresses a fusion protein composed of GAL4 DNA-binding domain fused to a truncated ARNT with its transactivation domain deleted, was kindly provided by Chris Bradfield (University of Wisconsin, Madison, WI, USA). The reporter plasmid pFR-Luc, which contains GAL4 response elements in the enhancer region that can drive luciferase expression, was obtained from Stratagene (La Jolla, CA, USA). The vectors pCI-XAP2 and pEYFP-mAHR was generated as previously described. ${ }^{38,39}$ pCMV- $\beta$-gal, which constitutively expresses $\beta$-galactosidase, was obtained from Clontech (Mountain View, CA, USA). 1-allyl-7-trifluoromethyl-1Hindazol-3-yl]-4-methoxyphenol (SGA360) was synthesized as previously described. ${ }^{37}$ Both $3^{\prime}, 4^{\prime}$-dimethoxy- $\alpha$-naphthoflavone (DiMNF) and $\alpha$-naphthoflavone $(\alpha \mathrm{NF})$ were purchased from Indofine. Structures of AHR ligands are shown in Supplementary Figure 1. Hepalclc7 and COS-1 cells were obtained from American Type Culture Collection.

\section{Mice}

Congenic $\mathrm{Ahr}^{-1-}$ mice on a C57BL6/J background were originally obtained from Dr Christopher Bradfield (University of Wisconsin). C57BL6/J mice congenic for the $A h^{d}$ allele and C57BL6/J mice were obtained Jackson (Bar Harbor, ME, USA) and bred in house. In all experiments 7- to 12-week-old male mice were used. All mice were maintained under a $12 \mathrm{~h}$ light/12 h dark cycle in a specific pathogen-free barrier facility.

\section{LPS Challenge}

Mice were intraperitoneally (i.p.) injected with SGA360 ( $20 \mathrm{mg} / \mathrm{kg}$ body weight) in corn oil for $2 \mathrm{~h}$ prior to an i.p. injection with 42.5 or $15 \mathrm{mg} / \mathrm{kg}$ of LPS ( $100 \mu \mathrm{l}$ per mouse) in PBS. In the high-LPS dose experiments an additional injection of SGA360 was given after $12 \mathrm{~h}$, also after $18 \mathrm{~h}$ mice were checked every $\mathrm{h}$ for lethality. After $48 \mathrm{~h}$ the surviving mice were killed.

\section{In Vivo Gout Model}

Mice were administered $300 \mu \mathrm{g}$ MSU crystal suspension in $10 \mu \mathrm{l}$ of PBS through injection into the articular space of the ankle using a 26-gauge syringe needle. MSU suspensions were sonicated prior to use. Subjects were topically treated with $30 \mu \mathrm{g}$ SGA360 in $20 \mu \mathrm{l}$ or vehicle (10\% DMSO, 90\% acetone) at $6 \mathrm{~h}$ intervals. Joint edema was accessed at $24 \mathrm{~h}$ intervals through micrometry and the weight of the joint.

\section{MSU-Induced Peritonitis Model}

Mice were i.p. injected with SGA360 $(25 \mathrm{mg} / \mathrm{kg})$ in corn oil for $2 \mathrm{~h}$ prior to an i.p. injection with MSU crystals $(25 \mathrm{mg} / \mathrm{kg})$ in PBS. Cells were collected by peritoneal lavage for flow cytometric analysis. A segment of ventral peritoneal tissue was excised posterior to the xiphoid cartilage for total RNA isolation and subsequent quantitative expression analysis.

\section{Flow Cytometric Analysis}

Total peritoneal cells from mice treated with SGA360 for $2 \mathrm{~h}$ prior to $6 \mathrm{~h}$ exposure to MSU crystal were lysed in hypotonic buffer to remove red blood cells. Cells were washed, resuspended in PBS with 1\% BSA, and counted using trypan blue. One million live cells were utilized for flow cytometric analysis conducted using a BD LSR Fortessa Cytometer and FlowJo software (Treestar). Cells are first gated on FSC/SSC to eliminate debris, and then live leukocytes were gated on CD45 + cells excluding the dead stain. These live leukocytes were then gated on either CD11b+F4/80+ (macrophages) or CD11b+ followed by analysis using Ly6G and Ly6C, the two components of the GR-1 receptor. Neutrophils express both Ly6G and Ly6C, whereas monocytes express only Ly6C.

\section{Preparation and Culture Conditions for Peritoneal Macrophages}

Mice were i.p. injected with $4 \mathrm{ml}$ of $3 \%$ thioglycolate. Cells were isolated after 3 days from the peritoneal cavity using a $10 \mathrm{ml}$ PBS wash coupled with shaking to suspend the cell in the PBS. Cells were centrifuged and resuspended in DMEM $+10 \%$ FBS+penicillin/streptomycin $+1 \mathrm{~mm}$ pyruvate. Cells were plated for $4 \mathrm{~h}$ and non-adherent cells were removed using a PBS wash. Cells were placed in the same medium for $18 \mathrm{~h}$ prior to treatments.

\section{Measurement of Cytokines/Chemokines}

Eve Technologies (Alberta, Canada) using ELISA measured the concentrations of cytokines and chemokines. In some experiments IL1B was measured using a Biolegend ELISA kit (San Diego, CA, USA).

\section{Cell Culture}

Hepa1c1c7 obtained from ATCC and DRE-driven stable reporter cell line H1L1.1c2 was kindly provided by Dr Michael Denison (University of CA, Davis, CA, USA) were maintained in $\alpha$-minimum essential medium (Sigma, St Louis, MO, USA), 10\% FBS, and penicillin/streptomycin. ${ }^{40}$

\section{Preparation of Cell Extracts}

Macrophage cultures were washed with ice-cold PBS, scraped into PBS, and centrifuged. For nuclear and cytosolic extracts, cell pellets were resuspended in MENG (25 mM MOPS, $2 \mathrm{~mm}$ EDTA, $0.02 \%$ sodium azide, and 10\% glycerol)+protease inhibitor cocktail (Roche) and homogenized with a stainlesssteel Dura-Grind dounce homogenizer (Wheaton Instruments, Millville, NJ, USA). Cell homogenate was centrifuged 
at $1000 \mathrm{~g}$ for $20 \mathrm{~min}$. The supernatant was then subjected to centrifugation at $42000 \mathrm{~g}$ for $30 \mathrm{~min}$ to generate cytosol. The pellet was washed three times with MENG, each time the nuclei was collected by centrifugation at $1000 \mathrm{~g}$ for $20 \mathrm{~min}$. The washed nuclei were extracted with MENG+500 $\mathrm{mm} \mathrm{NaCl}$ for $30 \mathrm{~min}$ and the extract collected after centrifugation. For phosphoprotein analysis macrophages were directly lysed in MENG+1\% Igepal CA-630+protease inhibitor cocktail (Roche)+PhosSTOP phosphatase inhibitors (Roche).

\section{Determination of AHR Transcriptional Activity in Peritoneal Lavage Extracts}

Mice were i.p. injected with $4 \mathrm{ml}$ of autoclaved $3 \%$ thioglycolate solution, after four days mice were i.p. injected with $400 \mu \mathrm{g}$ of MSU crystals in $100 \mu \mathrm{l}$ of sterile PBS. Crystal preparations were sonicated just prior to injection. After $6 \mathrm{~h}$ mice were killed, $4 \mathrm{ml}$ of PBS was i.p. injected and after rigorous shaking peritoneal lavage fluid was withdrawn with a syringe and placed in a $15-\mathrm{ml}$ centrifuge tube. An equal volume of anhydrous ethyl acetate was added and vortexed after $15 \mathrm{~min}$ samples were centrifuged at $5000 \mathrm{~g}$ for $30 \mathrm{~min}$. The ethyl acetate was transferred to another centrifuge tube with $10 \mathrm{mg}$ anhydrous sodium sulfate and mixed, after $10 \mathrm{~min}$ samples were centrifuged and the ethyl acetate dried in a $3 \mathrm{ml}$ reacti-vial under nitrogen. The residue was resuspended in $5 \mu \mathrm{l}$ DMSO. H1L1.1c2 stable reporter cells were plated in 12 well plates the day prior to treatment with $2 \mu \mathrm{l}$ of each sample. ${ }^{40}$ Luciferase activity was measured as previously described. $^{41}$

\section{Protein Blot Analysis}

Cell extracts were resolved on $8 \%$ tricine sodium dodecyl sulfate-polyacrylamide gel electrophoresis. After electrophoresis proteins were transferred to PVDF membrane. Proteins were detected using antibodies listed in Supplementary Table S1). Primary antibodies were visualized with species appropriate biotin-conjugated secondary antibodies (Jackson Immunoresearch, West Grove, PA, USA) and a subsequent incubation with ${ }^{125}$ I-streptavidin.

\section{One-Hybrid Mammalian Cell Assay}

Hepalc1c7 cells $(\sim 80 \%$ confluent $)$ were co-transfected with pG-ARNT/325, pFR-Luc, and pCMV- $\beta$-gal using Lipofectamine (Invitrogen) in Opti-MEM (Life Technologies, Grand Island, NY, USA) in 6-well dishes as described by the manufacturer. After $18 \mathrm{~h}$ cells were treated with AHR ligands for $6 \mathrm{~h}$, lysed in lysis buffer and luciferase measured as previously described. ${ }^{42} \beta$-galactosidase measured using the Promega $\beta$-galactosidase assay system and values were used to normalized the luciferase data.

\section{Cellular Localization Assay}

COS-1 cells obtained from ATCC were cultured in $35 \mathrm{~mm}$ dishes with $14 \mathrm{~mm}$ microwells with $1.5 \mathrm{~mm}$ gridded coverglass (MatTek Corporation, Ashland, MA, USA) in $\alpha$-minimum essential medium (Sigma). At $\sim 70 \%$ confluency cells were transfected with $0.75 \mu \mathrm{g}$ pEYFP/mAhR and $0.25 \mu \mathrm{g}$ pCI-XAP2 using LipofectaminePLUS in Opti-MEM (Life Technologies) as described by the manufacturer. The cells were cotransfected with a vector that expresses that XAP2, which helps to maintain AHR localization in the cytoplasm as previously described..$^{43}$ After $24 \mathrm{~h}$ cells were treated with AHR ligands and confocal microscopy performed. Cells were localized by light microscopy using the grid prior to taking a fluorescence image, after $1 \mathrm{~h}$ of AHR ligand treatment the same grid field of cells was identified by light microscopy and a fluorescence image captured.

\section{Real-Time Quantitative PCR}

RNA isolation and reverse transcription and quantitative PCR were performed as previously described. ${ }^{36}$ The PCR primers utilized can be found in Table S1.

\section{Chromatin Immunoprecipitation Assays}

Primary peritoneal macrophages were plated in $150-\mathrm{mm}$ cell culture dishes. Cells were pre-treated for $1 \mathrm{~h}$ with SGA360 $(10 \mu \mathrm{M})$, followed by LPS $(5 \mathrm{ng} / \mathrm{ml})$ for $4 \mathrm{~h}$. Chromatin Immunoprecipitation (ChIP) was performed using SimpleChIP Plus Enzymatic Chromatin IP kit (Cell Signaling Technology, Danvers, MA, USA) according to manufacturer's instructions. Overall, $8 \mu \mathrm{g}$ of digested chromatin was incubated overnight at $4{ }^{\circ} \mathrm{C}$ with the following antibodies: rabbit anti-AHR (Biomol International, Plymouth Meeting, PA, USA), rabbit anti-p65 (Cell Signaling Technology), normal rabbit IgG (Santa Cruz Biotechnology). Immunocomplexes were captured with Protein A/G PLUS-Agarose (Santa Cruz Biotechnology). Eluted DNA was purified using spin columns and analyzed by quantitative real-time PCR using primers listed in Supplementary Table S2.

\section{RNA-Sequencing Analysis}

Total RNA was isolated from primary peritoneal macrophages as previously described using TRI reagent (Sigma) in combination with the RNeasy purification kit (Qiagen, Hilden, Germany). Briefly, $70 \%$ ethanol was added to the aqueous phase after phase separation and transferred to RNeasy purification columns. RNA was extracted according to manufacturer's instructions. RNA quality was assessed on the Agilent Bioanalyzer using the RNA Nano assay. The RNA samples were then Poly-A selected and barcoded libraries were made from each sample using the Illumina TruSeq Stranded mRNA Library Prep Kit following the manufacturer's protocol. We then performed qPCR (Kapa kit) on all libraries to determine concentration. We made an equimolar pool of all barcoded libraries and sequenced the pool on the Illumina HiSeq 2500 in Rapid Run mode using 150 nt single read sequencing at the Genomics Core Facility (The Pennsylvania State University). RNA-seq reads were aligned to the Mus musculus genome (mm10, RefSeq genes) using TopHat version 2.0.13 with default parameters. ${ }^{44}$ Alignment 
results are given in Table S3. Reads mapping to genes were counted using HTseq-count version 0.5.4p3 with parameters '-s no -a 10 '. 45

\section{Gel-Shift Assays}

Gel-shift assays were performed with $500 \mathrm{~mm} \mathrm{NaCl}$ nuclear extracts isolated from $10 \mu \mathrm{M}$ SGA360, $5 \mathrm{ng} / \mathrm{ml}$ LPS, or SGA360/LPS-treated primary peritoneal macrophages. Three microgram of protein was added to gel-shift buffer, as described, ${ }^{46}$ to a final volume of $24 \mu \mathrm{l}$. The nuclear extract/ buffer mixture was incubated at $37^{\circ} \mathrm{C}$ for $15 \mathrm{~min}$. Mutant NF-kB oligonucleotide (500 ng) were added to corresponding extract mixtures and incubated at $37^{\circ} \mathrm{C}$ for $10 \mathrm{~min}$. In certain samples $500 \mathrm{ng}$ of NF-kB oligonucleotide was added. This was followed by the addition of $2.0 \times 10^{6} \mathrm{cpm}$ of ${ }^{32} \mathrm{P}$-labeled oligonucleotides containing a NF-kB response element; the mixtures were incubated at $37^{\circ} \mathrm{C}$ for $20 \mathrm{~min}$. The oligonucleotides used are as follows; NF-kB forward oligo, $5^{\prime}$-AGTT GAGGGGACTTTCCCAGG C-3', NF-kB reverse oligo, 5'-GCCTGGGAAAGTCCCCTCAACT-3', mutant NF-kB forward oligo, $5^{\prime}$-AGTTGAGGCGACTTTCCCAGGC-3' ${ }^{\prime}$, and mutant NF-kB reverse oligo, 5'-GCCTGGGAAAGTCGCC TCAACT-3'. The double-stranded oligonucleotides were radiolabeled as described. ${ }^{47}$ Following final incubation, $2 \mu \mathrm{l}$ of $0.25 \%$ xylene cyanol in $20 \% \mathrm{w} / \mathrm{v}$ Ficoll was added to each reaction. Samples were loaded onto a $6 \%$ non-denaturing polyacrylamide gel (Invitrogen) and separated by electrophoresis. The gels were fixed in a 7:1:1:1 water:methanol: acetic-acid:glycerol solution for $20 \mathrm{~min}$, dried for $40 \mathrm{~min}$, and then subjected to autoradiography for analysis. Relative band intensities were quantified using phosphorimager and OptiQuant software (Packard), and presented as digitized light units (DLU).

\section{Statistical Analysis}

Data are presented as the mean \pm s.e.m. Where appropriate, unpaired $t$-test or one-way ANOVA analyses with Tukey's multiple-comparison tests were performed with Prism software (GraphPad Software) to statistically analyze data.

\section{RESULTS \\ SGA360 Attenuates Sensitivity to LPS-Mediated Endotoxin Shock}

The previous observations that AHR expression inhibited LPS-mediated endotoxin shock coupled with the antiinflammatory activity of SGA360 led us to examine whether the SAhRM SGA360 can inhibit acute inflammation in an in vivo endotoxin shock model. ${ }^{10,37} \mathrm{C} 57 \mathrm{BL} 6 / \mathrm{J}-A h^{b}, \mathrm{C} 57 \mathrm{BL} 6 / \mathrm{J}-$ $A h^{d}$, and $A h r^{-1-}$ mice were injected i.p. with SGA360 $2 \mathrm{~h}$ prior to injection with LPS. In the $A h^{b}$ allele mice, SGA360 increased the $50 \%$ survival time from 28 to $42 \mathrm{~h}$ and $40 \%$ of the mice survived when pre-treated with SGA360 (Figures 1a and d). In contrast, SGA360 had no effect on survival of $A h^{d}$ allele mice (Figure $1 \mathrm{~b}$ ), this is consistent with lower affinity of the $\mathrm{AHR}^{\mathrm{d}}$ to AHR ligands observed in mice that express this
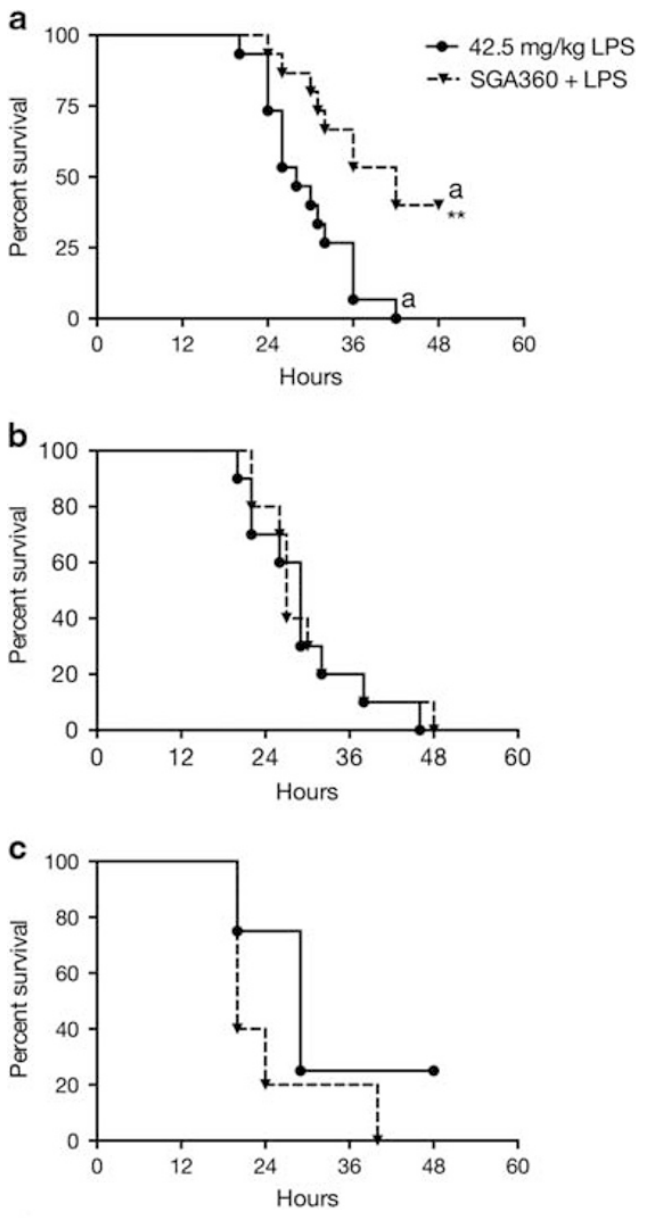

d

\begin{tabular}{|c|c|c|}
\hline \multirow{2}{*}{ Genotype } & \multicolumn{2}{|c|}{ Median survival time (h) } \\
\cline { 2 - 3 } & LPS & LPS + SGA360 \\
\hline $\mathrm{Ahr}^{\mathrm{b}}$ & 28 & 42 \\
\hline $\mathrm{Ahr}^{\mathrm{d}}$ & 29 & 27 \\
\hline $\mathrm{Ahr}^{-}$ & 29 & 20 \\
\hline
\end{tabular}

Figure 1 The $A h^{b}$ allele is required for SGA360-mediated attenuation of LPS-induced endotoxin shock. C57BL6/J- $A h^{\mathrm{b},} n=15$ (a), C57BL6/J- $A h^{\mathrm{d}}$, $n=10$ (b), and $A h r^{-/-}, n=5$ (c) mice were i.p. injected with SGA360 or carrier solvent $2 \mathrm{~h}$ prior to i.p. injection with LPS or phosphate-buffered saline. Every $12 \mathrm{~h}$ post-LPS injection mice were i.p. injected SGA360 or vehicle. Survival was assessed over $48 \mathrm{~h}$. This experiment was repeated twice with essentially the same result. (d) Summary of the median survival times for each genotype after LPS treatment. Data was statistically analyzed using a Kaplan-Meier survival curve analysis; ${ }^{*} P<0.005$.

form of the AHR. SGA360 failed to improve survival of mice that do not express the AHR (Figure 1c). Because of the number of defects in the immune system observed in AHR knockout mice, subsequent studies utilized a comparison of $A h^{b}$ and $A h^{d}$ mice. ${ }^{48-50}$

\section{SGA360 Attenuates the Levels of Inflammatory Mediators in Serum and Tissues After LPS Challenge}

Mice were injected i.p. with SGA360 $2 \mathrm{~h}$ prior to injection with LPS. After $4 \mathrm{~h}$ serum was collected and analyzed using 

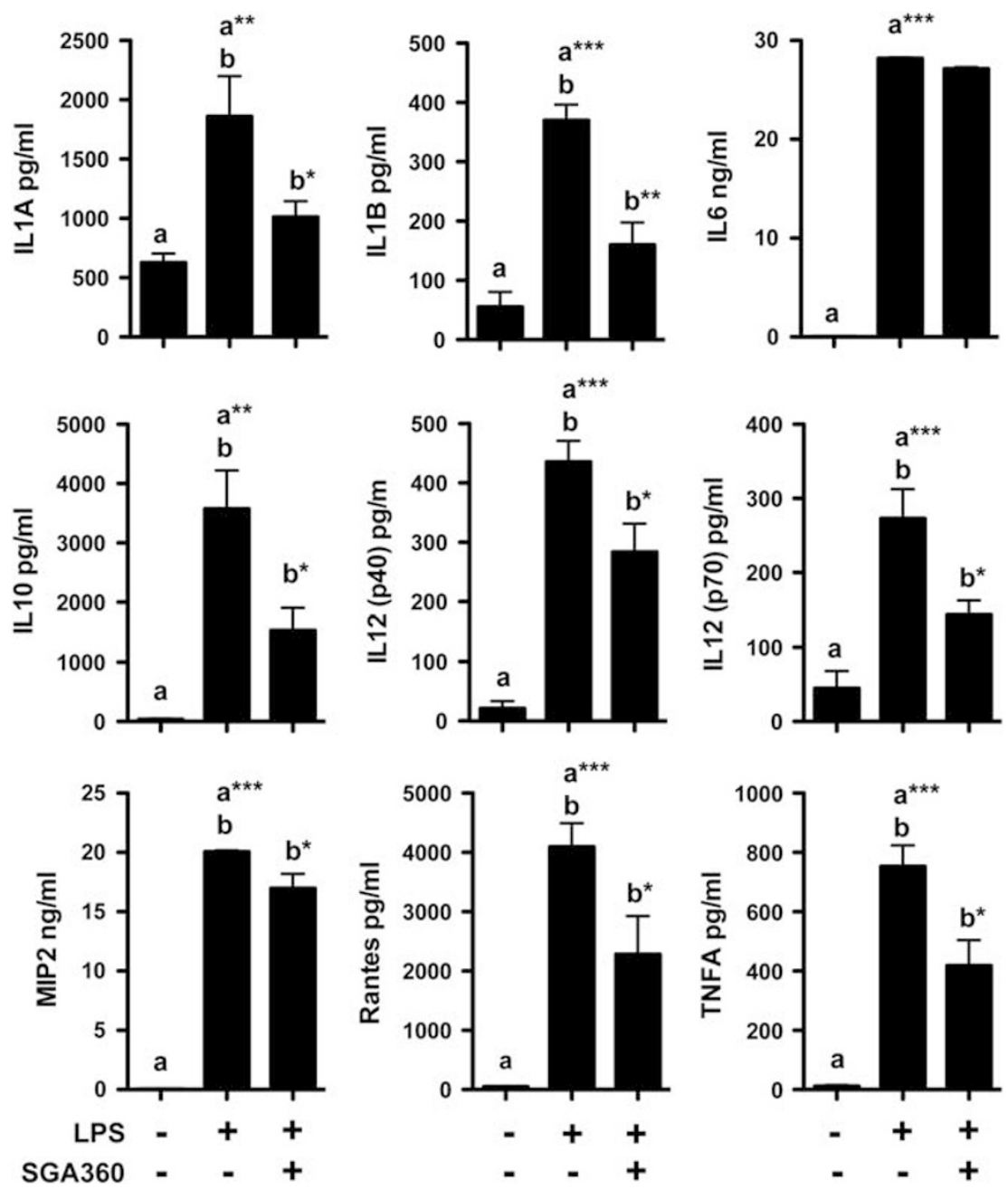

Figure 2 SGA360 attenuated the serum concentration of a variety of inflammatory mediators after LPS exposure. Mice were i.p. injected with SGA360 or carrier solvent, after $2 \mathrm{~h}$ mice were i.p. injected with LPS or phosphate-buffered saline. Serum was collected after $4 \mathrm{~h}$, and the levels of various cytokines/chemokines were determined by ELISA. Data were analyzed using one-way ANOVA followed by Tukey's multiple-comparison test. * $P<0.05$; ${ }^{*} P<0.01 ;{ }^{* *} P<0.001$. Alphabetical characters indicate statistical comparisons between two groups.

multiplex bead system. Results revealed that many of the key inflammatory mediators tested were significantly repressed by SGA360 including IL1A, IL1B, IL1A, IL12 (p70), MIP2, TNFA, and RANTES (Figure 2). In contrast, IL6 levels were not altered by SGA360 treatment. The anti-inflammatory cytokine IL-10 was also repressed. Expression of key inflammatory mediators in tissues was assessed by quantitative PCR analysis. SGA360 pretreatment significantly repressed LPS-mediated induction of $I l 1 b, I l 6$, Ptgs 2 , and Tnfa mRNA levels in lung (Figure 3). Similar results were also obtained in liver and kidney. Overall, these results are consistent with the ability of SGA360 to greatly enhance survival upon acute LPS challenge.

\section{SGA360 Inhibits MSU Crystal-Induced Joint Edema and Requires Expression of the $A H R^{b}$}

Another acute disease where macrophages have a key role in the development of inflammation is gout. ${ }^{1,51}$ Experiments were performed to establish the appropriate conditions to induce significant levels of ankle joint edema in a mouse model of gout. A MSU crystal dose-response and time-course experiments revealed that the dose of crystals required to mediate a significant induction of edema in an ankle joint was $300 \mu \mathrm{g}$ (Supplementary Figure 2S). Mice that lack AHR expression, or express either the $\mathrm{AHR}^{\mathrm{b}}$ or $\mathrm{AHR}^{\mathrm{d}}$ were subjected to MSU crystal-mediated joint edema and all genotypes yielded a similar level of joint edema upon MSU crystal treatment (Figure 4a). Next, we tested the ability of topical exposure to SGA360 to mitigate MSU-mediated joint edema. Two different concentrations of SGA360 yielded similar levels of repression, thus $30 \mu \mathrm{g}$ was chosen for all subsequent experiments (Figure 4b). All three Ahr genotypes were tested for the ability of SGA360 to repress edema (Figure 4c). SGA360 only significantly repressed edema in mice that express the high-ligand affinity $\mathrm{AHR}^{\mathrm{b}}$ form. This demonstrates that SGA360 binding to the AHR mediates the repressive effects observed. 
Lung
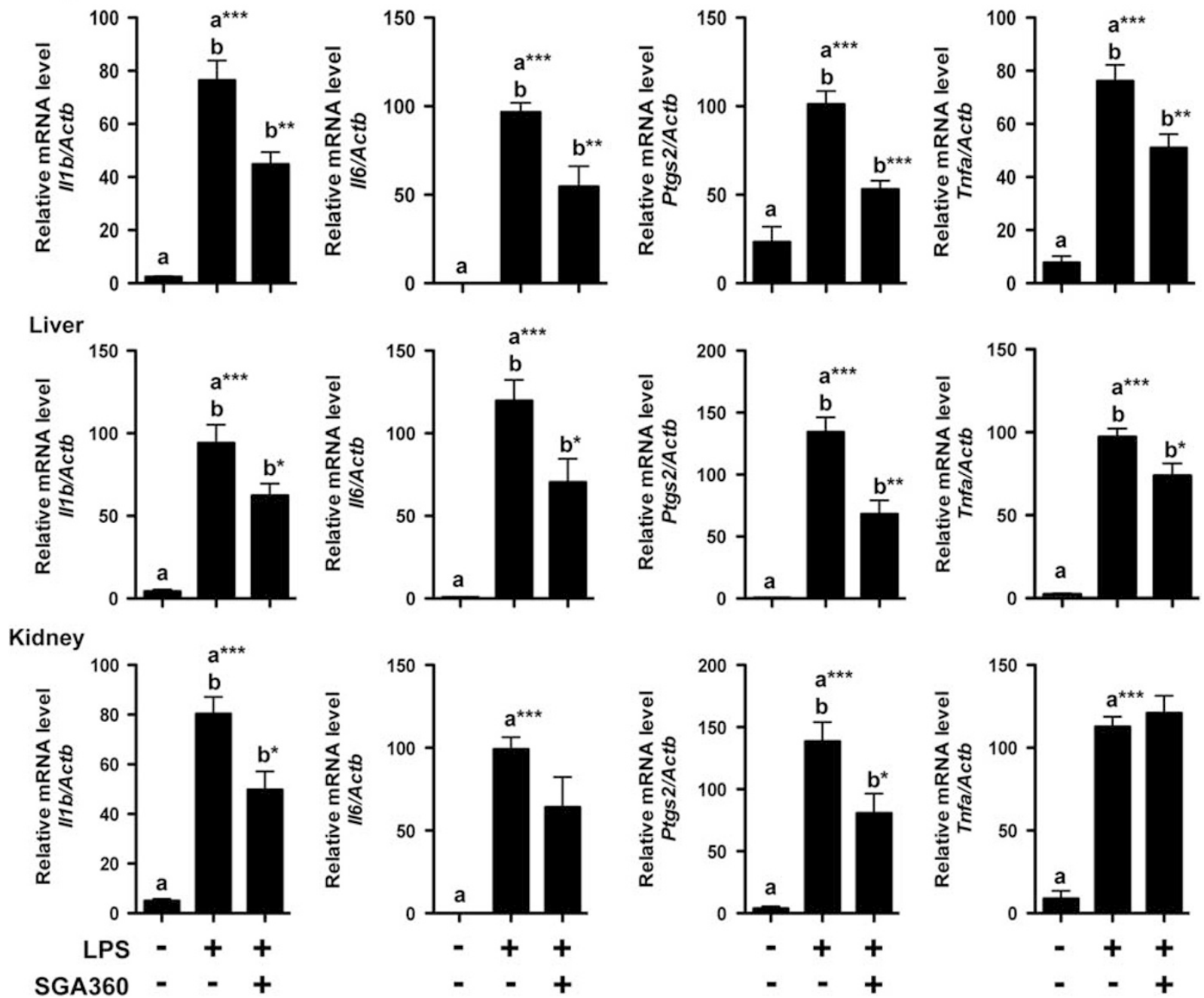

Figure 3 SGA360 inhibited the expression of several inflammatory mediators in lung, liver, and kidney after LPS exposure. Mice were treated as outlined in Figure 2 legends and the level of mRNA expression of several inflammatory mediators was determined.

\section{SGA360 Enhances Resolution of MSU Crystal-Induced Joint Edema}

We next wanted to test whether SGA360 would inhibit edema after the initial development of the disease. MSU crystals were used to induce edema for $24 \mathrm{~h}$, followed by treatment every $6 \mathrm{~h}$ with SGA360 for 3 days. A statistically significant $43 \%$ reduction in joint edema was observed after $12 \mathrm{~h}$ of SGA360 exposure (Figure 4d). This data would suggest that SAhRM have the potential to be utilized as a topical treatment.

\section{SGA360 Suppresses Inflammatory Response to Peritoneal MSU Crystal Exposure}

Because of the difficulty in performing detailed studies in mouse joints we decided to utilize a MSU crystal peritoneal model of acute gout that is often used for mechanistic studies on the role of macrophages and other immune cells. In a preliminary experiment, we examined the effect of MSU crystal dose on the migration of resident macrophages from the peritoneal cavity into tissues, an effect observed by others. ${ }^{1}$ A dose-dependent, five-fold reduction in the abundance of macrophages was observed in the peritoneal lavage relative to other cells at the lowest dose tested (Supplementary Figure 3S). In addition, MSU crystal exposure led to a significant increase in lavage fluid neutrophils (Supplementary Figure 4S). Subsequent experiments utilized $25 \mathrm{mg} / \mathrm{kg}$ of MSU crystals. The effect of SGA360 pretreatment on the peritoneal exudate cells in lavage fluid was assessed as depicted in Figure 5a. Live cells were analyzed for neutrophil, macrophage, and monocyte markers (Figure 5b). Treatment with SGA360 in the presence of MSU crystals resulted in a threefold reduction in the number of infiltrating neutrophils, and a twofold reduction in the number of macrophages and monocytes. The presence of MSU crystals in the peritoneum induces a rapid migration of macrophages into the surrounding tissues and macrophages 
a

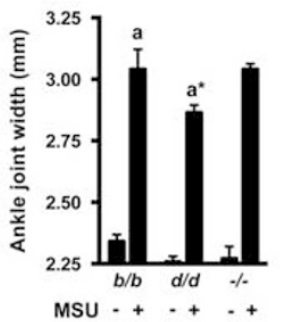

C

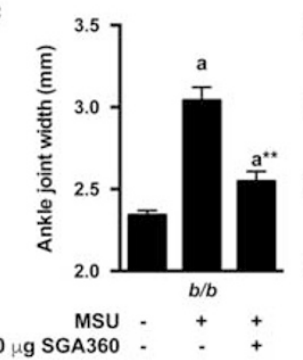

b

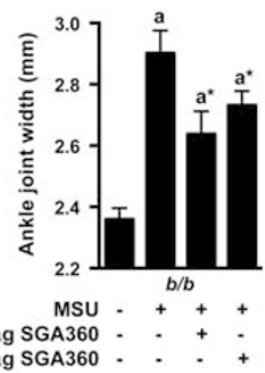

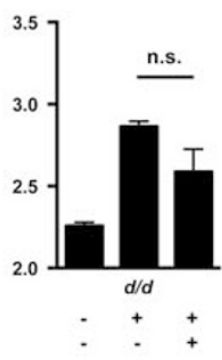
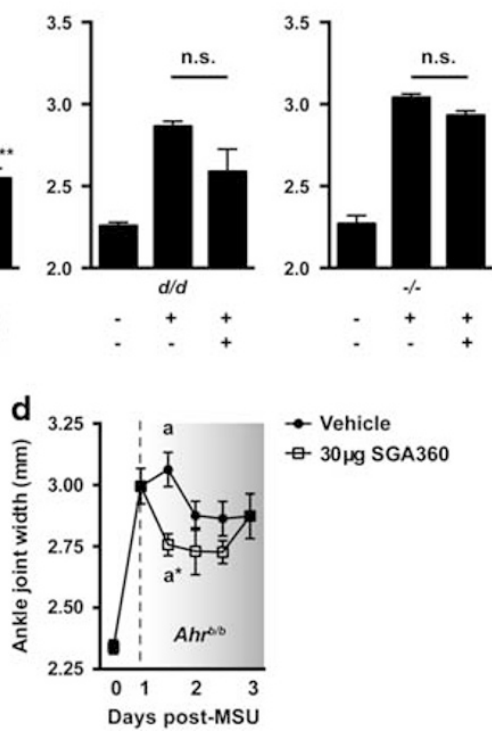

Figure $4 \mathrm{Ahr}$ genotype and treatment with SGA360 influences MSU crystal-induced joint edema. (a) C57BL6/J mice harboring the $A h^{b}, A h^{d}$, and $A h^{-1-}$ alleles were administered $10 \mu \mathrm{l}$ PBS or $300 \mu \mathrm{g}$ MSU suspension through injection into the articular space of the ankle. Joint edema was accessed $24 \mathrm{~h}$ post injection through micrometry. Data represent mean joint width $(\mathrm{mm}) \pm$ s.e.m. (b) Wild-type C57BL6/J mice harboring the highaffinity $A h^{b}$ allele were administered $10 \mu \mathrm{l}$ PBS or $300 \mu \mathrm{g}$ MSU suspension through injection into the articular space of the ankle. Immediately following MSU injection, joints were topically treated $(20 \mu \mathrm{l})$ with the indicated amount of SGA360 and thereafter at $6 \mathrm{~h}$ intervals. Joint edema was accessed $24 \mathrm{~h}$ post injection through micrometry. Data represent mean joint width $(\mathrm{mm}) \pm$ s.e.m. (c) C57BL6/J mice harboring $A h^{b}, A h^{d}$, and $A h^{-/-}$alleles were administered $10 \mu \mathrm{l}$ PBS or $300 \mu \mathrm{g}$ MSU suspension through injection into the articular space of the ankle. Immediately following MSU injection, joints were topically treated $(20 \mu \mathrm{l})$ with $30 \mu \mathrm{g}$ SGA360 and thereafter at $6 \mathrm{~h}$ intervals. Joint edema was accessed $24 \mathrm{~h}$ post injection through micrometry. Data represent mean joint width (mm) \pm s.e.m. (d) Wild-type C57BL6/J mice harboring the high-affinity $A h^{b}$ allele were administered $10 \mu \mathrm{l}$ PBS or $300 \mu \mathrm{g}$ MSU suspension through injection into the articular space of the ankle. Twenty-four hours following MSU injection, joints were topically treated $(20 \mu \mathrm{l})$ with vehicle (1:10 DMSO/acetone) or $30 \mu \mathrm{g} \mathrm{SGA360}$ and thereafter at $12 \mathrm{~h}$ intervals. Joint edema was accessed $24 \mathrm{~h}$ post injection and thereafter at $12 \mathrm{~h}$ intervals through micrometry. Data represent mean joint width $(\mathrm{mm}) \pm$ s.e.m.

can be detected bound to the peritoneum secreting cytokines. ${ }^{1}$ Thus, total RNA was isolated from peritoneal tissue near the ventral midline and the levels of several major inflammatory mediators expressed by macrophages were

assessed (Figure 5c). SGA360 pretreatment significantly attenuated the level of expression of Cxcl1, Cxcl2, Il1b, and Mrcl suggesting that either the number of adherent inflammatory cells is reduced or the level of inflammatory signaling is decreased within the adherent cell population.

\section{MSU Crystals Exposure Mediates an Increase in the Production of AHR Activators}

We hypothesized that immune cell inflammatory activity could lead to the formation of AHR ligands, which would enhance inflammatory signaling. To test this hypothesis mice were exposed to thioglycolate to elicit macrophage migration into the peritoneum followed by treatment with MSU crystals. After $6 \mathrm{~h}$ a peritoneal lavage was performed and the isolated fluid was extracted with ethyl acetate. Hepal DRE-driven reporter cell line was treated with dried and resuspended extracts. Lavage fluid from MSU-treated mice induced an $\sim 10$-fold increase in AHR-mediated reporter activity compared to controls (Figure 6). These results suggest that MSU crystals elicit an increase in AHR transcriptional activity, likely through the presence of AHR ligand(s).

\section{SGA360 Represses Expression of an Array of Inflammatory and AHR Regulated Genes Upon LPS Exposure in Cultured Macrophages}

Considering that macrophages have a critical role in the progression of septic shock and MSU crystal-mediated gout, we wanted to examine the ability of SGA360 to alter inflammatory signaling after LPS treatment. Macrophages were pre-treated with SGA360 for $1 \mathrm{~h}$ prior to exposure to LPS for $4 \mathrm{~h}$, mRNA was isolated and sequenced. Data analysis revealed that SGA360 significantly inhibited expression of a number of genes found in toll receptor, acute-phase, and inflammation pathways (Figures $7 \mathrm{a}-\mathrm{c}$ ). Eight of the most LPS-induced inflammatory genes were further examined by qRT-PCR and the results confirmed a significant level of repression by SGA360 (Figure 7d). In addition, we determined that two direct AHR target genes, Ahrr and Cyp1b1 are significantly repressed by SGA360 exposure (Figure 7e). In contrast, Cyp1a1 was not induced by LPS, perhaps since it is known that inflammatory signaling represses Cyplal expression. ${ }^{52}$ These results would suggest that SGA360 is capable of repressing inflammatory signaling in LPS-treated cultured primary macrophages and AHR target gene expression.

\section{SGA360 Inhibits LPS-Mediated Inflammatory Signaling in Cultured Macrophages}

Next, we wanted to ask the question whether SGA360 binding to the $A H R^{b}$ compared to the low-affinity $A H R^{d}$ is required for the repression of inflammatory signaling observed in the RNA-seq experiment. Peritoneal macrophages isolated from mice were cultured for $24 \mathrm{~h}$ prior to treatment with SGA360 and LPS. The potent agonist TCDD in combination with LPS synergistically induced Ptgs2 mRNA levels 
a

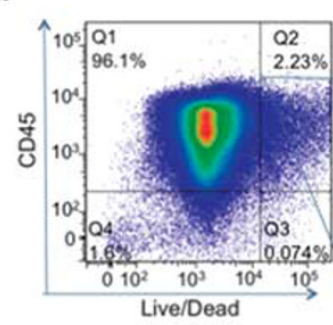

Myeloid Cell Population 93.9\%
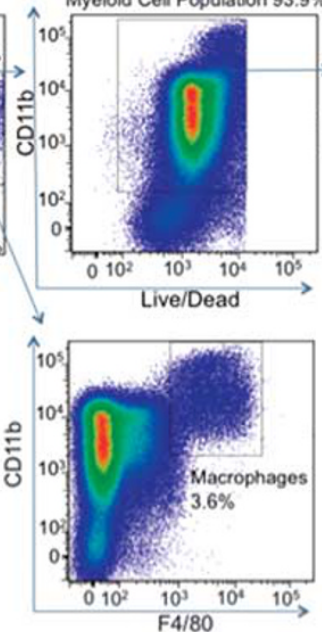
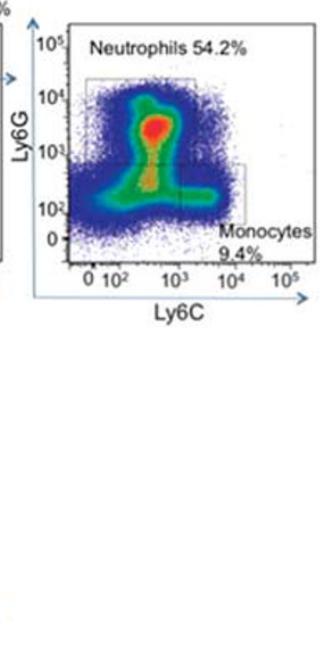

C

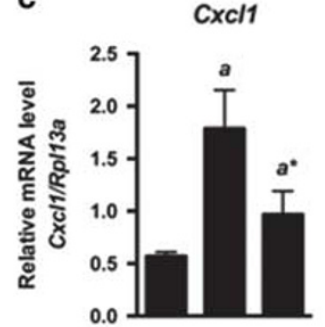

II1b

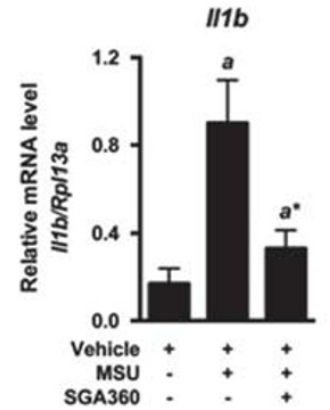

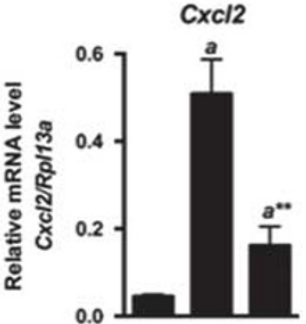

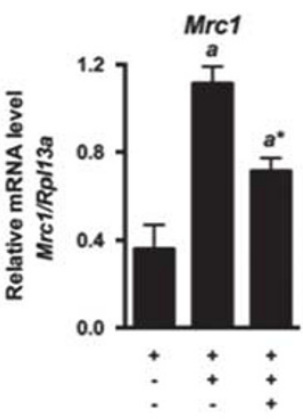

b
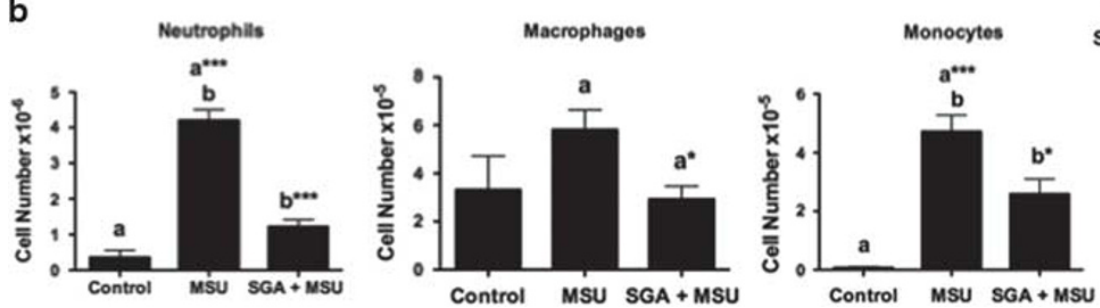

Figure 5 SGA360 attenuates MSU crystal-mediated peritoneal infiltration of immune cells. C57BL6/J-Ah ${ }^{b}$ mice were i.p. injected with either 20 mg/kg (body weight) SGA360 or carrier solvent for $2 \mathrm{~h}$ prior to i.p. injection with $25 \mathrm{mg} / \mathrm{kg}$ (body weight) MSU crystals for $6 \mathrm{~h}$. (a) Cells in the peritoneum were isolated by lavage and live cells analyzed by flow cytometric analysis as shown. (b) The number of neutrophils, macrophages, and monocytes were determined. (c) A segment of peritoneal tissue was analyzed for mRNA expression levels of four genes involved in neutrophil/macrophage inflammatory signaling and chemotaxis.

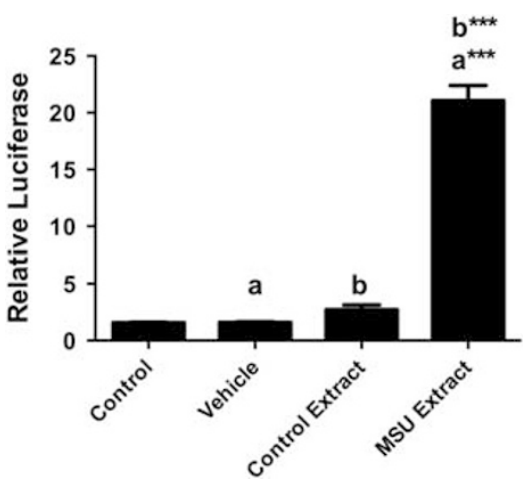

Figure 6 MSU crystals increase the production of AHR ligands in the peritoneum. Macrophages were elicited with thioglycolate in C57BL6/J$A h^{b}$ mice followed by i.p. injection with MSU crystals $(25 \mathrm{mg} / \mathrm{kg})$. After $6 \mathrm{~h}$, cells in the peritoneum were isolated by lavage, extracted with ethyl acetate, dried, and resuspended in DMSO. H1L1.1c2 stable reporter cells were treated as shown for $4 \mathrm{~h}$ and luciferase activity determined.

(Figure 8). In contrast, SGA360 mediated a significant repression in Il1b, Il6, Tnfa, and Ptgs2 mRNA levels. Treatment of cultured macrophages isolated from congenic Ahr $r^{d}$ mice with AHR ligands and LPS revealed a lack of
SGA360-mediated repression of inflammatory signaling, except for modest repression of Illb (Figure 8). We have previously determined that $\mathrm{Ccl} 20$ is synergistically induced by TCDD and IL1B treatment and thus is an AHR target gene. ${ }^{53}$ Therefore, macrophages were treated with LPS and the effect of SGA360 on Ccl20 expression was examined. SGA360 significantly repressed LPS-mediated Ccl20 expression (Supplementary Figure 6S), whereas TCDD and LPS synergistically induced $\mathrm{Ccl} 20$ expression. These results indicate that SGA360 represses inflammatory signaling in primary macrophages in a high-affinity $\mathrm{AHR}^{\mathrm{b}}$-dependent fashion.

\section{DiMNF Inhibits LPS-Mediated Inflammatory Signaling in Cultured Macrophages}

In a previous report the AHR ligand, DiMNF that exhibited SAhRM activity was characterized. ${ }^{35}$ The ability of this ligand to modulate inflammatory signaling in peritoneal macrophages was assessed. The LPS-mediated expression levels of $I l 1 b$, Il6, Ptgs2, and Tnfa were all significantly repressed in $A h r^{b}$ mouse-derived macrophages by DiMNF pretreatment (Supplementary Figure 7S). In contrast, DiMNF failed to alter LPS-mediated expression of the inflammatory markers in macrophages isolated from $A h r^{d}$ mice. In these studies, we did 
a

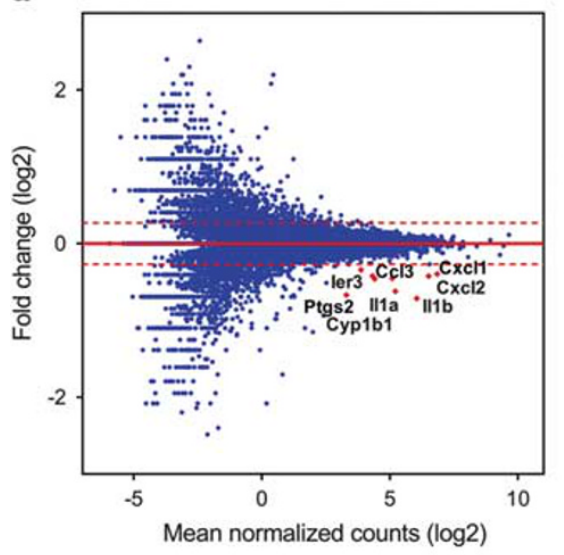

c

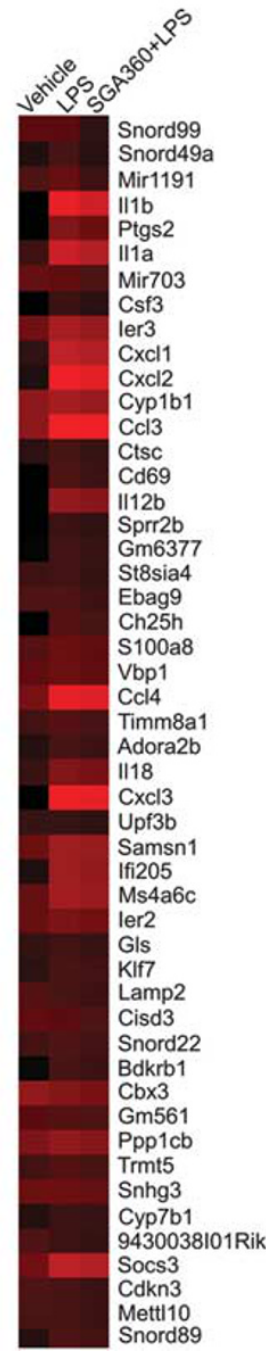

b

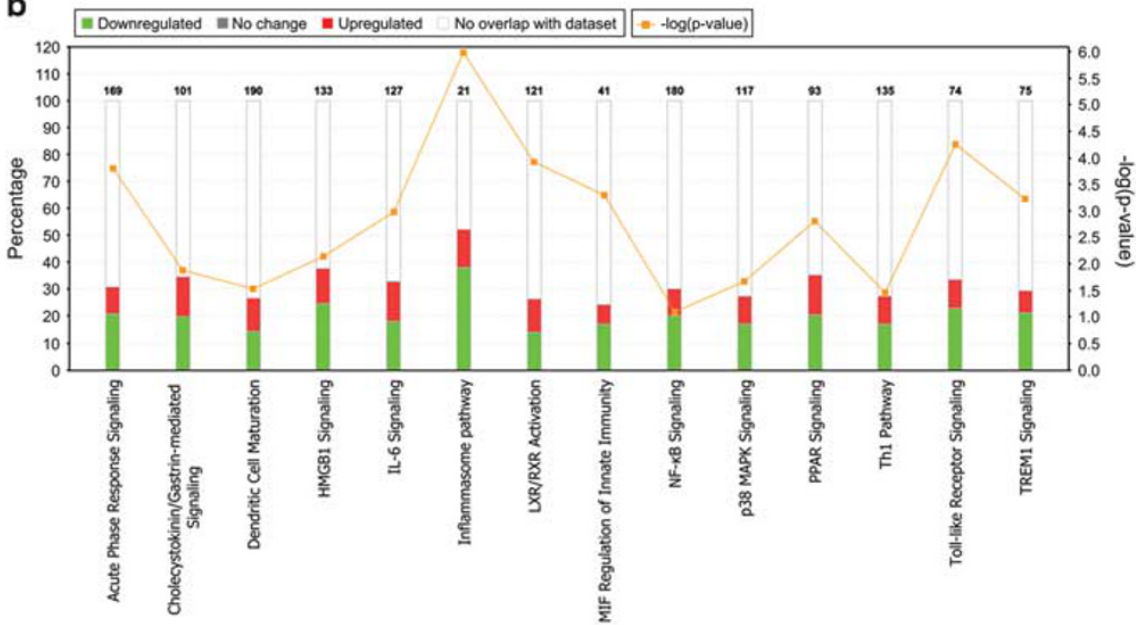

d
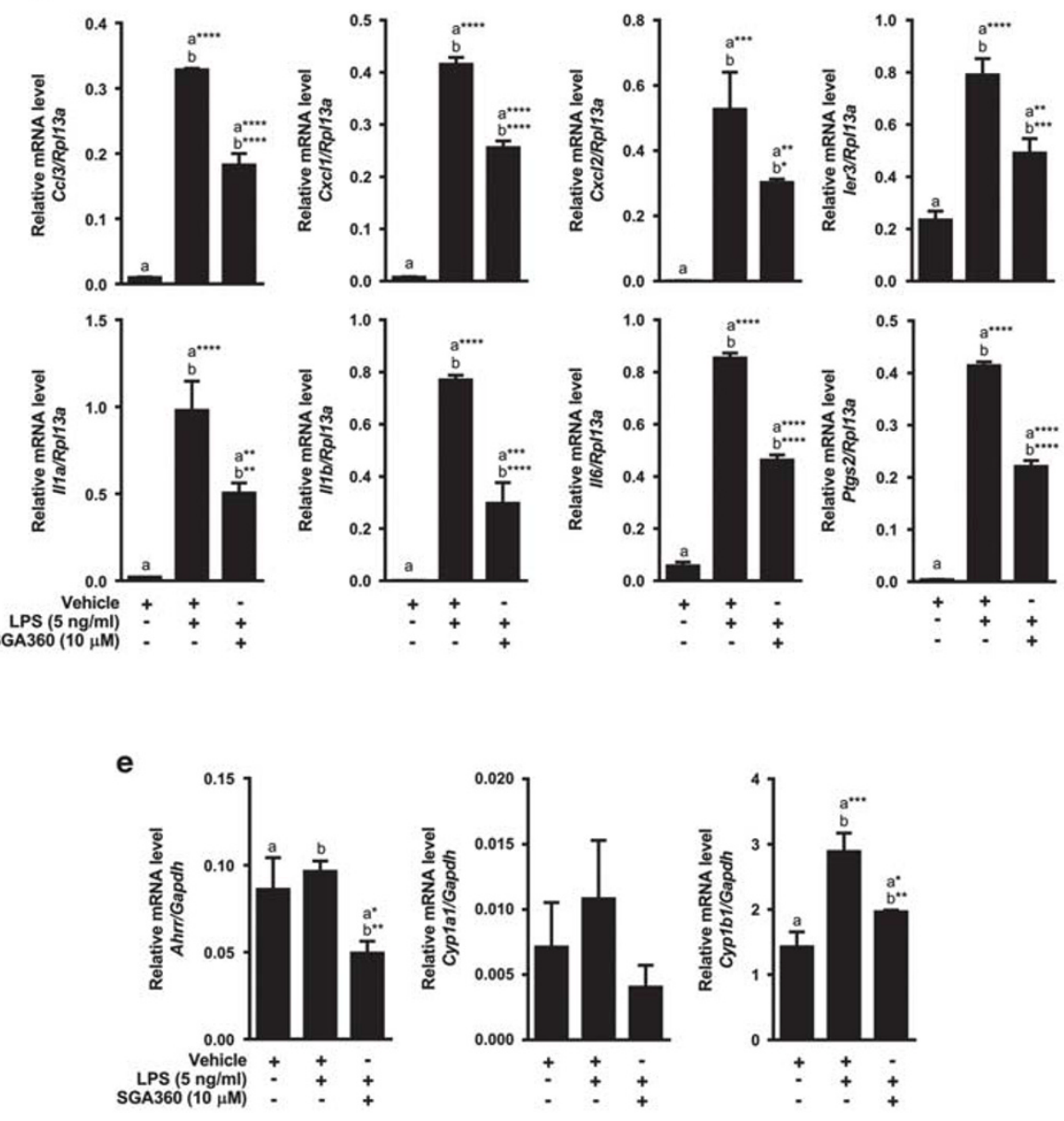

Figure 7 Comparison of the ability of an AHR agonist, antagonist and selective Ah receptor modulator to alter LPS-mediated inflammatory signaling in primary macrophages. Primary peritoneal macrophages cultures derived from C57BL6/J-Ah ${ }^{b}$ or C57BL6/J-Ah mice were treated with AHR ligands as indicated, after $1 \mathrm{~h}$ cells were treated with LPS or phosphate-buffered saline for $4 \mathrm{~h}$. Total RNA was isolated and the relative mRNA levels of Ptgs2, II1b, 116 , and Tnfa were assessed through qRT-PCR. The data represents mean mRNA level normalized to Actb mRNA expression \pm SD. $(n=3$ per treatment group; $\left.{ }^{*} P<0.05,{ }^{* *} P<0.01,{ }^{* * *} P<0.001\right)$. 

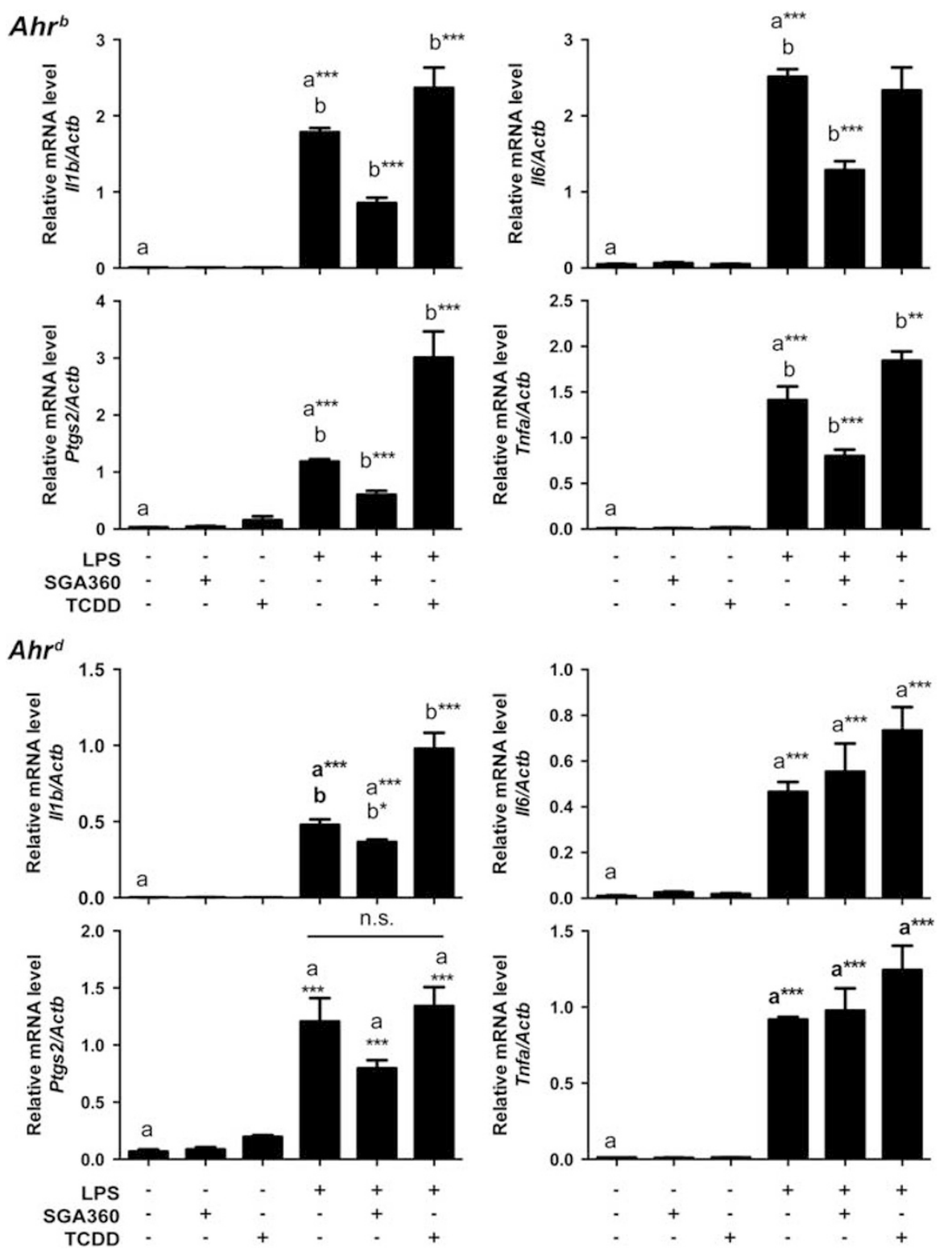

Figure 8 RNA-sequencing identified a set of genes differentially expressed upon SGA360 treatment in peritoneal macrophages. (a) MA plot representation of the gene expression data. The plot was obtained using Graphpad Prism, where M ( $Y$ axis) represents the intensity ratio of [SGA360 + LPS] to [LPS] treatment; fold change $\left(\log _{2}\right)$, and A ( $X$ axis) represents the average intensity of two treatment groups. Red dots represent the highly expressed genes downregulated by SGA360. (b) Ingenuity Pathway Analysis revealed top canonical pathways altered upon SGA360 treatment. For a given pathway, green bars indicate the percentage of downregulated genes, and red bars indicate the percentage of upregulated genes. (c) Heatmap and histogram for a subset of genes that were downregulated by SGA360. Each cell represents the normalized gene expression value, log (RPKM), for a given gene (row) in the specified treatment group (column). Cell colors indicate gene expression level; red: high expression, black: low expression.

not utilize macrophages from $\mathrm{Ahr}^{-1-}$ mice because flow cytometry analysis indicated that the resident population of macrophages were twofold less than in wild-type mice, thus casting doubt on the usefulness of these mice as controls for in vitro studies (Supplementary Figure 5S).

\section{Inhibition of Nuclear NF-kB Activity}

NF-kB has a key role in modulating the expression of various inflammatory cytokines involved in sepsis, thus we wanted to examine the effect of SGA360 on NF-kB signaling. Pretreatment of primary macrophage cultures with SGA360 prior to LPS exposure led to a 50\% decrease in the p65 levels present in nuclear extracts (Figure 9a). However, SGA360 did not inhibit p65 translocation into the nucleus after LPS treatment (Supplementary Figure 8S). The NF-kB binding to a consensus p65/p50 response element was assessed by EMSA. The results revealed a significant decrease in binding after pretreatment with SGA360, consistent with the nuclear p65 
a
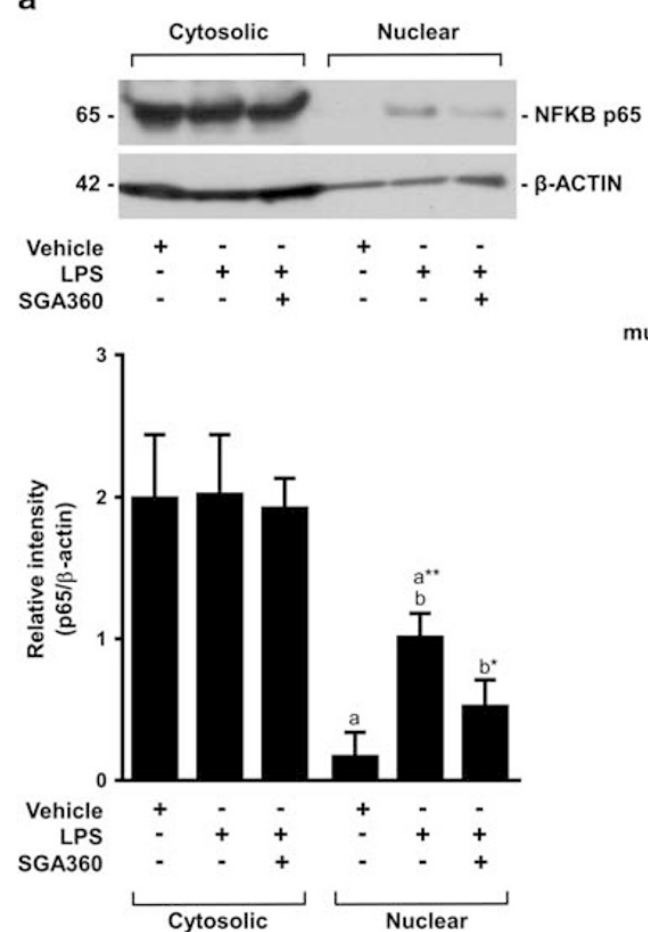

b

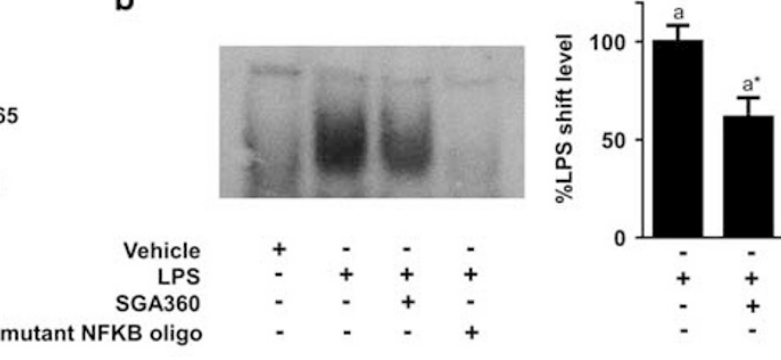

C

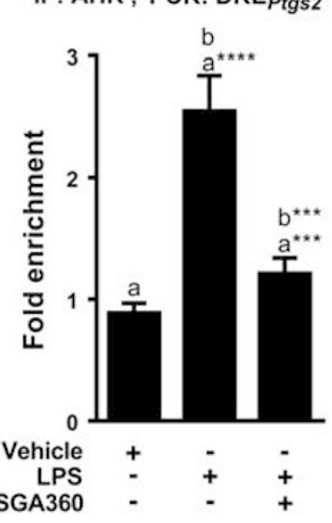

IP: P65, PCR: DRE Ptgs2

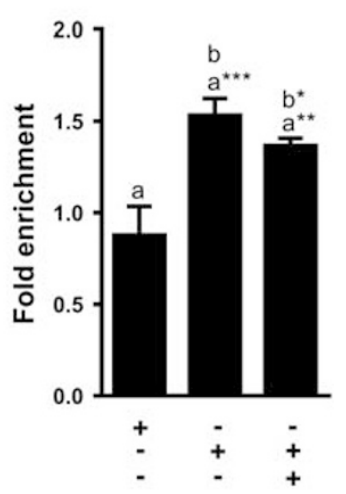

Figure 9 SGA360 exposure decreases macrophage nuclear levels of p65 after LPS treatment and AHR occupancy on the Ptgs2 promoter. (a) Primary elicited peritoneal macrophages were treated with $10 \mu \mathrm{m}$ SGA360 $1 \mathrm{~h}$ prior to exposure to $10 \mathrm{ng} / \mathrm{ml}$ LPS for $4 \mathrm{~h}$ as indicated. Nuclear and cytoplasmic levels of p65 and $\beta$-actin levels were determined. The experiment in a was performed in triplicate and the relative levels of p65 expression was quantitated. (b) Macrophages were treated as in a and nuclear extracts were subjected in gel-shift analysis for the presence of NF-kB binding to its cognate response element and quantitated. (c) Primary elicited peritoneal macrophages were treated with $10 \mu \mathrm{m}$ SGA360 $1 \mathrm{~h}$ prior to exposure to 10 ng/ $\mathrm{ml}$ LPS for $1 \mathrm{~h}$. ChIP analyses were performed to assess of presence of the AHR and p65 on the Ptgs 2 promoter, the level of occupancy was determined using quantitative PCR.

levels observed in Figure 9a (Figure 9b). Through promoter analysis the AHR has been demonstrated to enhance Ptgs2 transcription in combination with NF-kB. ${ }^{54}$ We performed ChIP assays to examine AHR and p65 occupancy of the Ptgs2 promoter. Interestingly, there was a threefold increase in AHR occupancy of the Ptgs2 promoter upon LPS exposure, and SGA360 pretreatment resulted in an 50\% decrease in AHR occupancy and a modest but significant reduction in p65 occupancy of the Ptgs 2 promoter (Figure 9c). These results are consistent with decrease in Ptgs 2 mRNA levels observed in macrophages after SGA360 pretreatment (Figure 8).

\section{SGA360 Fails to Increase AHR Transcriptional Activity or Induce Nuclear Translocation}

In a mammalian one-hybrid transient assay TCDD elicited recruitment of the AHR to ARNT/325/Gal4 and mediate transcriptional activity (Figure 10a). In this assay, the transactivation domain of ARNT is deleted, thus heterodimerization with AHR will induce transcriptional activity. As a relatively weak positive control the partial AHR agonist $\alpha$ naphthoflavone is capable of significantly inducing transcriptional activity, this demonstrates that the assay is sensitive to
AHR agonist activity. In contrast, the SAhRMs DiMNF and SGA360 both failed to induce AHR-mediated transcriptional activity, even at $20 \mu \mathrm{M}$ concentration (Figure 10a). This data further reinforces previous studies that determined that DiMNF and SGA360 fail to exhibit AHR agonist activity. ${ }^{35,37}$ Whether SGA360 was capable of inducing nuclear retention of AHR in the nucleus of primary macrophages was examined (Figure 10b). The results revealed that SGA360 did not increase AHR levels retained in the nucleus, when compared to TCDD as a positive control. In addition, SGA360 failed to reduce overall AHR levels, which is observed in the presence of an agonist. The next question we wanted to address is whether SGA360 alters the localization of the AHR. To assess this COS- 1 cells were transfected with a vector that expresses human AHR-YFP. After $24 \mathrm{~h}$ cells were visualized, followed by treatment of cells with either TCDD or SGA360 for $1 \mathrm{~h}$. The same fields of cells were assessed by confocal microscopy and images were obtained before and after ligand treatments. Arrows mark the key cells illustrating that TCDD induces translocation into the nucleus (Figure 10). In contrast, SGA360 failed to induce translocation and in fact appears to mediate less nuclear AHR localization. 


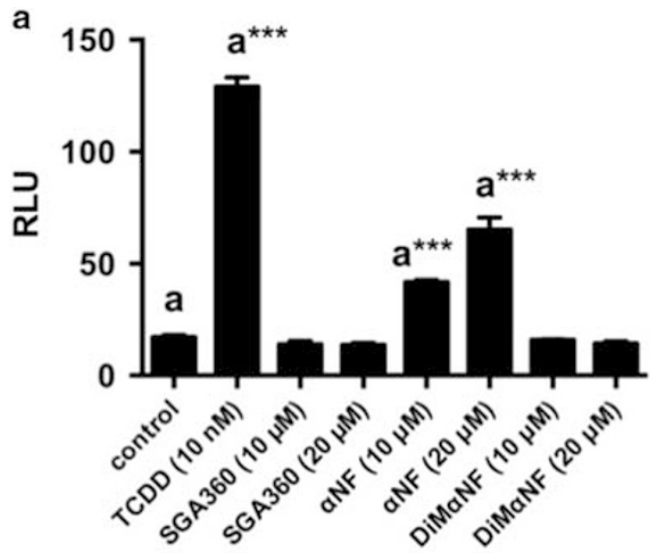

c

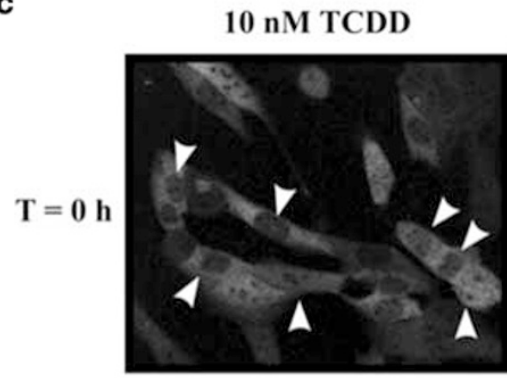

$10 \mathrm{nM}$ TCDD

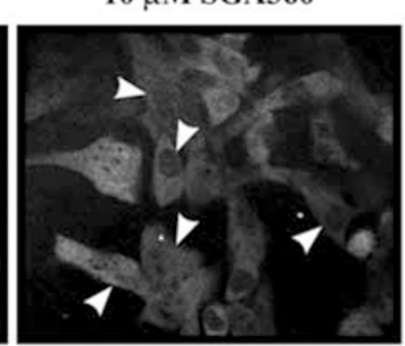

b

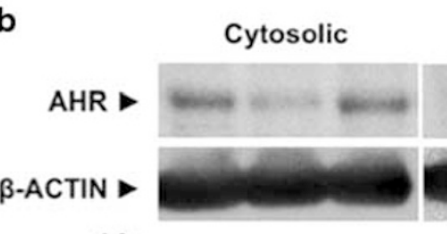

Nuclear
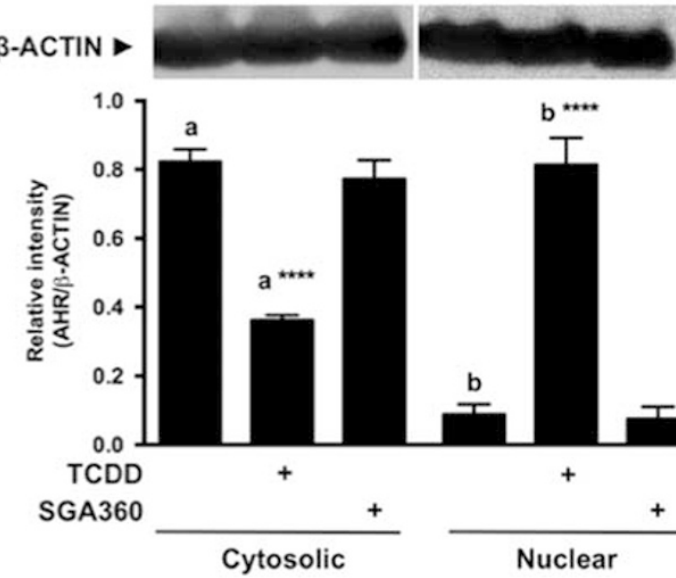

$\mathbf{T}=+\mathbf{l} \mathbf{h}$
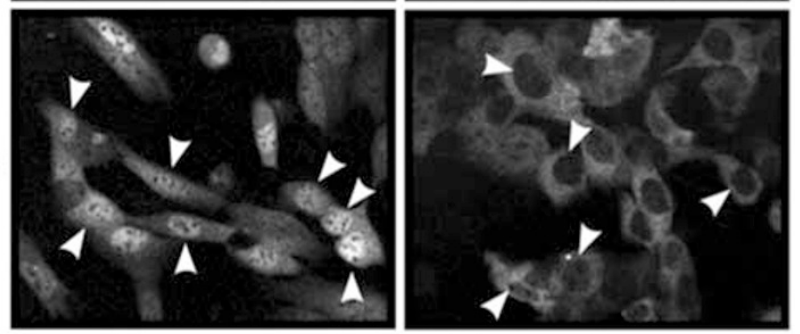

Figure 10 SGA360 fails to exhibit transcription activity or induce nuclear translocation. (a) Hepa1c1c7 cells were transfected with with pG-ARNT/325, pFR-Luc, and pCMV- $\beta$-gal, $18 \mathrm{~h}$ after transfection cells were treated with AHR ligands for $6 \mathrm{~h}$. Cell were lyzed and $\beta$-galactosidase activity was

determined. (b) Primary elicited peritoneal macrophages were cultured for $24 \mathrm{~h}$ followed by treatment with either $2 \mathrm{nM}$ TCDD or $10 \mu \mathrm{m}$ SGA360 for $1 \mathrm{~h}$. Cells were lysed, cytosolic and nuclear extracts isolated followed by SDS-PAGE. The relative level of AHR was determined by quantitative protein blot analysis. (c) COS-1 cells were transfected with pEYFP-mAHR, after $24 \mathrm{~h}$ cells were imagined by confocal fluorescence microscopy and treated with AHR ligands for $1 \mathrm{~h}$ and imagined again.

\section{DISCUSSION}

The ability to survive septic shock requires the use of antibiotics and the management of the cytokine storm that occurs from a systemic infection. One strategy for inhibition of inflammation is to target a specific inflammatory mediator, such as COX2, IL1B, or TNFA, either with chemical inhibitors or more recently with biologics. Although this approach can be effective in chronic inflammatory conditions, there is a need to develop broader based treatment strategies, especially in acute inflammatory conditions. The AHR has emerged as an important modulator of both innate and adaptive immunity. Thus, considering the ability to effectively modulate AHR transcriptional activity with different ligands, the AHR may be a useful therapeutic target. Previous studies have shown that $\mathrm{Ahr}^{-/-}$mice are more susceptible to LPS exposure than WT mice at a sub-lethal dose of LPS $(10-25 \mathrm{mg} / \mathrm{kg}) .{ }^{10,55}$ In contrast, we performed LPS-mediated shock at a dose of $42.5 \mathrm{mg} / \mathrm{kg}$, which led to $100 \%$ lethality in WT mice within $48 \mathrm{~h}$. Under these conditions of acute endotoxemia, whether the AHR is not expressed in mice, or is the $A h^{b}$ or $A h^{d}$ allelic form, the median survival time was essentially the same. These conditions were chosen to address whether treatment with SGA360 would alter survival. The results revealed that SGA360 pretreatment both increased survival time from 28 to $42 \mathrm{~h}$, and perhaps most importantly led to a $40 \%$ survival rate in $A h^{b}$ mice. In contrast, SGA360 exhibited no protective effect on $A h^{d}$, which is consistent with lesser AHR ligandmediated effects with the low ligand affinity form of the AHR. These results support the concept that SGA360 mediates its protective effects in vivo through binding to the AHR. Although these effects do not involve AHR-mediated agonist 
activity, others have demonstrated that an AHR agonist can also exhibit a protective effect in an LPS septic shock model. ${ }^{10}$ Their results suggested that an AHR agonist led to an enhanced plasminogen activator inhibitor-2 (PAI-2) expression in an ARNT-independent manner. However, in our studies PAI-2 levels are not altered by SGA360 treatment of macrophages (unpublished data). Thus, our in vivo results presented here appear to be achieved through different mechanism(s), such as inhibition of AHR target gene expression.

The AHR is an important mediator of inflammatory signaling through combinatorial regulation of a growing list of genes, including Il6, Illb, Il2, and Ptgs2..$^{5,56-58}$ The proposed mechanism of this activity on the Il6 promoter is through the ability of AHR/ARNT heterodimer to bind DRE in the promoter upstream from the more proximal response elements that bind NF-kB, and perhaps other inflammatory transcription factors, leading to HDAC1 dismissal and subsequent acetylation of NF-kB. ${ }^{23}$ We have also determined that treatment with an AHR antagonist can in effect displace the AHR from the IL6 and IL1B promoters and reduce IL6 and $I L 1 B$ expression. ${ }^{59,60}$ In the studies presented here it is apparent that the ability of SGA360 to enhance retention of the AHR in the cytoplasm is consistent with the antagonistic activity previously observed with SGA360. ${ }^{37}$ RNA-seq data presented in this study revealed that the AHR target gene Cyp1b1 is abundantly expressed in LPS-treated primary mouse macrophages and is repressed threefold by SGA360. A previous study had determined that CYP1B1 is a major P450 expressed in human macrophages. ${ }^{61}$ CYP1B1 is capable of metabolizing arachidonic acid, released during inflammatory signaling, leading to the formation of various hydroxyeicosatetretraenoic and epoxyeicosatrienoic fatty acids that likely participate in inflammatory signaling. ${ }^{62}$ Interestingly, our previous studies have demonstrated that certain eicosanoids are AHR ligands. ${ }^{41,63}$ Importantly, macrophages in Cyp1b1 null mice exhibit impaired ability in the phagocytosis of apoptotic, necrotic, and opsonized cells. ${ }^{64}$ This likely indicates that these macrophages would exhibit a decrease in phagocytic function. A second AHR target gene Ahrr is also significantly repressed by SGA360 in LPS-treated macrophages. Interestingly, Ahrr null mice are highly resistant to endotoxin-mediated shock. ${ }^{65}$ The AHR and inflammatory signaling through p38 kinase signaling and/or NF-kB activation directly regulate both Cyp1b1 and Ahrr gene expression in a combinatorial manner. ${ }^{66,67}$ These observations coupled with SGA360-mediated repression of Ccl20 expression, which is also regulated directly by the AHR, supports the concept that AHR antagonism may be at least partially responsible for the attenuation of LPS-mediated shock observed here. ${ }^{53}$ Interestingly, treatment of macrophages with LPS leads to a approximate twofold increase in AHR levels after $24 \mathrm{~h}$ (unpublished data) and is consistent with recently published studies in dendritic cells. ${ }^{68}$ The ability of NF-kB to induce AHR levels would support the concept that in the presence of an AHR agonist during activated inflammatory signaling the AHR may exhibit enhanced transcriptional activity further driving the inflammatory response. Furthermore, the actual level of SGA360 attenuation of local inflammation would likely be dependent on the AHR ligand status at that site.

A number of studies have indicated that the expression of the AHR in macrophages is anti-inflammatory. ${ }^{10}$ In $\mathrm{Ahr}^{-/-}$ macrophages in vitro exposure to LPS results in heightened inflammatory signaling when compared to WT macrophages. ${ }^{69,70}$ Proposed mechanisms of these antiinflammatory activities include the formation of a STAT1/ AHR complex, inhibition of NLRP3 expression, and induction of plasminogen activator inhibitor-2 expression. ${ }^{71}$ In addition, crystalline silica-induced lung inflammation in vivo and inflammatory signaling in macrophages in vitro are enhanced in the absence of AHR expression. ${ }^{72}$ Whether the AHR is liganded or unliganded in these studies is not clear, but it is likely that the majority of the receptor resides in the cytoplasm. This would suggest that expression of AHR in macrophages attenuates inflammatory signaling perhaps through inhibition of NF-kB-mediated signaling. ${ }^{73}$ However, we have determined that AHR does not inhibit NF-kB translocation into the nucleus or occupancy on the Ptgs2 promoter after LPS treatment of macrophages. Thus, the AHR has emerged as a factor that exhibits both inflammatory and anti-inflammatory activities, dependent on the presence of AHR ligands and whether the AHR is present in the cytoplasm or induced to heterodimerize with ARNT. In addition, the presence of other transcription factors in the nucleus could lead to combinatorial regulation that in context-specific. An example of a possible in vivo scenario is during a lung infection with $P$. aeruginosa, which produces precursors of pigmented factors that are AHR ligands, these small molecules participate in the enhancement of the host inflammatory response. ${ }^{30}$ As the infection is cleared and AHR agonist levels are reduced the unliganded cytoplasmic AHR then attenuates inflammatory signaling.

In the MSU crystal-mediated joint edema model, SGA360 markedly inhibited joint edema. It is generally believed that MSU crystals activate macrophages that leads to a cascade of inflammatory signaling, especially IL1B secretion. ${ }^{4}$ This in turn, leads to CXCL1 and CXCL2 expression and direct activation of invading neutrophils. Both of these genes were repressed in cultured LPS-treated macrophages exposed to SGA360. Considering how small a joint is in mice we decided to examine the influence of MSU crystals on inflammatory signaling in a peritonitis model, which will allow direct examination of the effect of MSU crystals and SGA360 on the resident and invading macrophage populations. A marked increase in monocyte population was seen with MSU crystal exposure, whereas SGA360 pretreatment attenuated MSU crystal-mediated recruitment of neutrophils and monocytes into the peritoneum. These results are likely due to SGA360mediated inhibition of resident macrophage-mediated 
inflammatory signaling. One possible activity that SGA360 could exhibit is the ability to inhibit AHR agonist activity and thus exhibit antagonist potential. Indeed, organic solvent extracts of peritoneal lavage fluid after MSU crystal treatment were capable of inducing AHR transcriptional activity and thus may participate in vivo in enhancing inflammatory signaling.

There is increasing evidence that there are three basic types of ligands: full agonist (eg, TCDD), antagonists (eg, GNF351), and SAhRMs (SGA360, DiMNF), although there are also weak or partial agonists, such as $\alpha$-naphthoflavone. Previous results would suggest that AHR agonists can exhibit both agonist activity and SAhRM activity. As SGA360 exerts its effects in the cytoplasm and does not exhibit agonist activity, it is plausible that in the presence of an agonist it would act as an antagonist in vivo. However, in cultured primary macrophage experiments and in the MSU crystal joint edema model, the antagonist GNF351 failed to exhibit antiinflammatory activity. This would suggest that SGA360 antiinflammatory activity is likely through several mechanisms, and not just AHR antagonism. What is emerging is an ability of the AHR in the cytoplasm of the cells to mediate antiinflammatory activity perhaps in an unliganded state or in the presence of a SAhRM. Whether there are endogenous or dietary SAhRMs will be an important possibility to explore.

In addition, the glucocorticoid receptor has been shown to modulate NF-KB activity in the cytoplasm. ${ }^{74}$ This provides a precedent for the ability of the AHR to attenuate inflammatory signaling through cytoplasmic activity. The inability of SGA360 to induce translocation of the AHR into the nucleus of cells would indicate that the anti-inflammatory activity of SGA360 may be mediated through protein-protein interactions within the cytoplasm. Furthermore, deletion of ARNT expression from macrophages had no effect on survival in a toxic shock model, suggesting that the ability of the AHR to inhibit inflammatory signaling in macrophages is through a non-DRE-driven mechanism. ${ }^{10}$

In summary, these studies support three main conclusions. The first is that the SGA360 inhibited acute inflammation in an AHR-dependent manner. Second, one mechanism of SGA360-mediated repression of inflammatory signaling is through inhibition of NF-KB nuclear retention. Third, these studies established SAhRMs as a class of AHR ligands with considerable anti-inflammatory potential to treat acute inflammatory diseases such as gout. Finally, this work can provide the basis for the development of more potent higher affinity SAhRMs useful for further exploring clinical applications.

Supplementary Information accompanies the paper on the Laboratory Investigation website (http://www.laboratoryinvestigation.org)

\section{ACKNOWLEDGMENTS}

We thank the Penn State Microscopy and Cytometry Facility_University Park, PA, USA for flow cytometric and confocal microscopy analysis. We thank the
Penn State Genomics Core Facility-University Park, PA, USA for RNAsequencing. We also thank Marcia $\mathrm{H}$ Perdew for excellent editorial assistance. This work was supported in part by NIH RO1ES004869 and RO1ES019964 and the Smith Endowment to GHP.

\section{DISCLOSURE/CONFLICT OF INTEREST}

The authors declare no conflict of interest.

1. Martin WJ, Walton M, Harper J. Resident macrophages initiating and driving inflammation in a monosodium urate monohydrate crystalinduced murine peritoneal model of acute gout. Arthritis Rheum 2009:60:281-289.

2. Cailhier JF, Partolina M, Vuthoori S, et al. Conditional macrophage ablation demonstrates that resident macrophages initiate acute peritoneal inflammation. J Immunol 2005;174:2336-2342.

3. Shi Y, Mucsi AD, Ng G. Monosodium urate crystals in inflammation and immunity. Immunol Rev 2010;233:203-217.

4. Mitroulis I, Kambas K, Ritis K. Neutrophils, IL-1 beta, and gout: is there a link? Semin Immunopathol 2013;35:501-512.

5. Chen CJ, Shi Y, Hearn A, et al. MyD88-dependent IL-1 receptor signaling is essential for gouty inflammation stimulated by monosodium urate crystals. J Clin Invest 2006;116:2262-2271.

6. Cavagna L, Taylor WJ. The emerging role of biotechnological drugs in the treatment of gout. Biomed Res Int 2014;2014:264859.

7. Huet $\mathrm{O}$, Chin-Dusting JP. Septic shock: desperately seeking treatment. Clin Sci 2014;126:31-39.

8. Martin GS, Mannino DM, Eaton S, et al. The epidemiology of sepsis in the United States from 1979 through 2000. N Engl J Med 2003;348: 1546-1554.

9. Casey LC, Balk RA, Bone RC. Plasma cytokine and endotoxin levels correlate with survival in patients with the sepsis syndrome. Ann Intern Med 1993;119:771-778.

10. Sekine H, Mimura J, Oshima $M$, et al. Hypersensitivity of aryl hydrocarbon receptor-deficient mice to lipopolysaccharide-induced septic shock. Mol Cell Biol 2009;29:6391-6400.

11. Beischlag TV, Luis Morales J, Hollingshead BD, et al. The aryl hydrocarbon receptor complex and the control of gene expression. Crit Rev Eukaryot Gene Expr 2008;18:207-250.

12. Bunger $M K$, Glover $E$, Moran $S M$, et al. Abnormal liver development and resistance to 2,3,7,8-tetrachlorodibenzo-p-dioxin toxicity in mice carrying a mutation in the DNA-binding domain of the aryl hydrocarbon receptor. Toxicol Sci 2008;106:83-92.

13. Petrulis JR, Perdew GH. The role of chaperone proteins in the aryl hydrocarbon receptor core complex. Chem Biol Interact 2002;141: $25-40$.

14. Ikuta T, Tachibana T, Watanabe J, et al. Nucleocytoplasmic shuttling of the aryl hydrocarbon receptor. J Biochem 2000;127:503-509.

15. Vogel CF, Sciullo E, Li W, et al. RelB, a new partner of aryl hydrocarbon receptor-mediated transcription. Mol Endocrinol 2007;21:2941-2955.

16. Puga A, Barnes SJ, Dalton TP, et al. Aromatic hydrocarbon receptor interaction with the retinoblastoma protein potentiates repression of E2F-dependent transcription and cell cycle arrest. J Biol Chem 2000;275:2943-2950.

17. Huang G, Elferink CJ. Multiple mechanisms are involved in Ah receptormediated cell cycle arrest. Mol Pharmacol 2005;67:88-96.

18. Beischlag TV, Perdew GH ER. alpha-AHR-ARNT protein-protein interactions mediate estradiol-dependent transrepression of dioxin-inducible gene transcription. J Biol Chem 2005;280:21607-21611.

19. McMillan BJ, Bradfield CA. The aryl hydrocarbon receptor sans xenobiotics: endogenous function in genetic model systems. Mol Pharmacol 2007;72:487-498.

20. Quintana FJ, Sherr DH. Aryl hydrocarbon receptor control of adaptive immunity. Pharmacol Rev 2013;65:1148-1161.

21. Poland $A$, Teitelbaum $P$, Glover $E$, et al. Stimulation of in vivo hepatic uptake and in vitro hepatic binding of [125I]2-lodo-3,7,8trichlorodibenzo-p-dioxin by the administration of agonist for the Ah receptor. Mol Pharmacol 1989;36:121-127.

22. Ryu BW, Roy S, Sparrow BR, et al. Ah receptor involvement in mediation of pyruvate carboxylase levels and activity in mice given 2,3,7,8-tetrachlorodibenzo-p-dioxin. J Biochem Toxicol 1995;10: 103-109. 
23. DiNatale BC, Schroeder JC, Francey LJ, et al. Mechanistic insights into the events that lead to synergistic induction of interleukin 6 transcription upon activation of the aryl hydrocarbon receptor and inflammatory signaling. J Biol Chem 2010;285:24388-24397.

24. Prigent $L$, Robineau M, Jouneau $S$, et al. The aryl hydrocarbon receptor is functionally upregulated early in the course of human T-cell activation. Eur J Immunol 2014;44:1330-1340.

25. Stange J, Veldhoen $M$. The aryl hydrocarbon receptor in innate $T$ cell immunity. Semin Immunopathol 2013;35:645-655.

26. Denison MS, Soshilov AA, He G, et al. Exactly the same but different: promiscuity and diversity in the molecular mechanisms of action of the aryl hydrocarbon (dioxin) receptor. Toxicol Sci 2011;124:1-22.

27. Jin UH, Lee SO, Sridharan G, et al. Microbiome-derived tryptophan metabolites and their aryl hydrocarbon receptor-dependent agonist and antagonist activities. Mol Pharmacol 2014;85:777-788.

28. Bjeldanes LF, Kim JY, Grose KR, et al. Aromatic hydrocarbon responsiveness-receptor agonists generated from indole-3-carbinol in vitro and in vivo: comparisons with 2,3,7,8-tetrachlorodibenzop-dioxin. Proc Natl Acad Sci U S A 1991;88:9543-9547.

29. Schroeder JC, Dinatale BC, Murray IA, et al. The uremic toxin 3-indoxyl sulfate is a potent endogenous agonist for the human aryl hydrocarbon receptor. Biochemistry 2010;49:393-400.

30. Moura-Alves P, Fae K, Houthuys $E$, et al. AhR sensing of bacterial pigments regulates antibacterial defence. Nature 2014;512:387-392.

31. Mezrich JD, Fechner $\mathrm{JH}$, Zhang $\mathrm{X}$, et al. An interaction between kynurenine and the aryl hydrocarbon receptor can generate regulatory T cells. J Immunol 2010;185:3190-3198.

32. Smith KJ, Murray IA, Tanos $\mathrm{R}$, et al. Identification of a high affinity ligand that exhibits complete Ah receptor antagonism. J Pharmacol Exp Ther 2011;338:318-327.

33. Kim SH, Henry EC, Kim DK, et al. Novel compound 2-methyl-2Hpyrazole-3-carboxylic acid (2-methyl-4-o-tolylazo-phenyl)-amide (CH-223191) prevents 2,3,7,8-TCDD-induced toxicity by antagonizing the aryl hydrocarbon receptor. Mol Pharmacol 2006;69:1871-1878.

34. Boitano $A E$, Wang J, Romeo $\mathrm{R}$, et al. Aryl hydrocarbon receptor antagonists promote the expansion of human hematopoietic stem cells. Science 2010;329:1345-1348.

35. Murray IA, Flaveny CA, Chiaro CR, et al. Suppression of cytokinemediated complement factor gene expression through selective activation of the Ah receptor with $3^{\prime}, 4^{\prime}$-dimethoxy-alpha-naphthoflavone. Mol Pharmacol 2011;79:508-519.

36. Murray IA, Morales JL, Flaveny CA, et al. Evidence for ligand-mediated selective modulation of aryl hydrocarbon receptor activity. Mol Pharmacol 2010;77:247-254.

37. Murray IA, Krishnegowda G, DiNatale BC, et al. Development of a selective modulator of aryl hydrocarbon (Ah) receptor activity that exhibits anti-inflammatory properties. Chem Res Toxicol 2010;23: 955-966.

38. Meyer BK, Pray-Grant MG, Vanden Heuvel JP, et al. Hepatitis B virus $\mathrm{X}$-associated protein 2 is a subunit of the unliganded aryl hydrocarbon receptor core complex and exhibits transcriptional enhancer activity. Mol Cell Biol 1998;18:978-988.

39. Petrulis JR, Hord NG, Perdew GH. Subcellular localization of the aryl hydrocarbon receptor is modulated by the immunophilin homolog hepatitis B virus X-associated protein 2. J Biol Chem 2000;275: 37448-37453.

40. Garrison PM, Tullis K, Aarts JM, et al. Species-specific recombinant cell lines as bioassay systems for the detection of 2,3,7,8-tetrachlorodibenzo-p-dioxin-like chemicals. Fundam Appl Toxicol 1996;30: 194-203.

41. Chiaro CR, Morales JL, Prabhu KS, et al. Leukotriene A4 metabolites are endogenous ligands for the Ah receptor. Biochemistry 2008;47: 8445-8455.

42. Murray IA, Perdew GH. Omeprazole stimulates the induction of human insulin-like growth factor binding protein-1 through aryl hydrocarbon receptor activation. J Pharmacol Exp Ther 2008;324:1102-1110.

43. Ramadoss $P$, Petrulis JR, Hollingshead BD, et al. Divergent roles of hepatitis $B$ virus $X$-associated protein 2 (XAP2) in human versus mouse Ah receptor complexes. Biochemistry 2004;43:700-709.

44. Trapnell C, Pachter L, Salzberg SL. TopHat: discovering splice junctions with RNA-Seq. Bioinformatics 2009;25:1105-1111.

45. Anders S, Huber W. Differential expression analysis for sequence count data. Genome Biol 2010;11:R106.
46. Singh SS, Hord NG, Perdew GH. Characterization of the activated form of the aryl hydrocarbon receptor in the nucleus of HeLa cells in the absence of exogenous ligand. Arch Biochem Biophys 1996;329:47-55.

47. Denison MS, Fisher JM, Whitlock Jr JP . Inducible, receptor-dependent protein-DNA interactions at a dioxin-responsive transcriptional enhancer. Proc Natl Acad Sci USA 1988;85:2528-2532.

48. Fernandez-Salguero P, Pineau T, Hilbert DM, et al. Immune system impairment and hepatic fibrosis in mice lacking the dioxin-binding Ah receptor. Science 1995;268:722-726.

49. Lee JS, Cella M, McDonald KG, et al. AHR drives the development of gut ILC22 cells and postnatal lymphoid tissues via pathways dependent on and independent of Notch. Nat Immunol 2011;13:144-151.

50. Wagage S, John B, Krock BL, et al. The aryl hydrocarbon receptor promotes IL-10 production by NK cells. J Immunol 2014;192: 1661-1670.

51. Martin WJ, Shaw O, Liu X, et al. Monosodium urate monohydrate crystal-recruited noninflammatory monocytes differentiate into $\mathrm{M} 1$ like proinflammatory macrophages in a peritoneal murine model of gout. Arthritis Rheum 2011;63:1322-1332.

52. Morgan ET. Regulation of cytochromes P450 during inflammation and infection. Drug Metab Rev 1997;29:1129-1188.

53. Lahoti TS, Boyer JA, Kusnadi A, et al. Aryl hydrocarbon receptor activation synergistically induces lipopolysaccharide-mediated expression of proinflammatory chemokine (c-c motif) ligand 20. Toxicol Sci 2015;148:229-240.

54. Yang F, Bleich D. Transcriptional regulation of cyclooxygenase-2 gene in pancreatic beta-cells. J Biol Chem 2004;279:35403-35411.

55. Bessede A, Gargaro M, Pallotta MT, et al. Aryl hydrocarbon receptor control of a disease tolerance defence pathway. Nature 2014;511: 184-190.

56. Hollingshead BD, Beischlag TV, Dinatale BC, et al. Inflammatory signaling and aryl hydrocarbon receptor mediate synergistic induction of interleukin 6 in MCF-7 cells. Cancer Res 2008;68:3609-3617.

57. Lahoti TS, John K, Hughes JM, et al. Aryl hydrocarbon receptor antagonism mitigates cytokine-mediated inflammatory signalling in primary human fibroblast-like synoviocytes. Ann Rheum Dis 2013;72: 1708-1716.

58. Jeon MS, Esser C. The murine IL-2 promoter contains distal regulatory elements responsive to the Ah receptor, a member of the evolutionarily conserved bHLH-PAS transcription factor family. J Immunol 2000;165:6975-6983.

59. Dinatale BC, Perdew GH. Ah receptor antagonism inhbits constitutive and cytokine inducible IL6 production in head and neck tumor cell lines. Mol Carcinog 2011;50:173-183.

60. Lahoti TS, Hughes JM, Kusnadi A, et al. Aryl hydrocarbon receptor antagonism attenuates growth factor expression, proliferation, and migration in fibroblast-like synoviocytes from patients with rheumatoid arthritis. J Pharmacol Exp Ther 2014;348:236-245.

61. Baron JM, Zwadlo-Klarwasser G, Jugert F, et al. Cytochrome P450 1B1: a major P450 isoenzyme in human blood monocytes and macrophage subsets. Biochem Pharmacol 1998;56:1105-1110.

62. Choudhary D, Jansson I, Stoilov I, et al. Metabolism of retinoids and arachidonic acid by human and mouse cytochrome P450 1b1. Drug Metab Dispos 2004;32:840-847.

63. Chiaro CR, Patel RD, Perdew GH. 12(R)-Hydroxy-5(Z),8(Z),10(E),14(Z)eicosatetraenoic acid [12(R)-HETE], an arachidonic acid derivative, is an activator of the aryl hydrocarbon receptor. Mol Pharmacol 2008;74: 1649-1656.

64. Ward JM, Nikolov NP, Tschetter JR, et al. Progressive glomerulonephritis and histiocytic sarcoma associated with macrophage functional defects in CYP1B1-deficient mice. Toxicol Pathol 2004;32:710-718.

65. Brandstatter O, Schanz O, Vorac J, et al. Balancing intestinal and systemic inflammation through cell type-specific expression of the aryl hydrocarbon receptor repressor. Sci Rep 2016;6:26091.

66. Smerdova L, Smerdova J, Kabatkova M, et al. Upregulation of CYP1B1 expression by inflammatory cytokines is mediated by the p38 MAP kinase signal transduction pathway. Carcinogenesis 2014;35: 2534-2543.

67. Baba T, Mimura J, Gradin K, et al. Structure and expression of the Ah receptor repressor gene. J Biol Chem 2001;276:33101-33110.

68. Vogel CF, Khan EM, Leung PS, et al. Cross-talk between aryl hydrocarbon receptor and the inflammatory response: a role for nuclear factor-kappaB. J Biol Chem 2014;289:1866-1875. 
69. Kimura A, Naka T, Nakahama T, et al. Aryl hydrocarbon receptor in combination with Stat1 regulates LPS-induced inflammatory responses. J Exp Med 2009;206:2027-2035.

70. Masuda K, Kimura A, Hanieh $\mathrm{H}$, et al. Aryl hydrocarbon receptor negatively regulates LPS-induced IL-6 production through suppression of histamine production in macrophages. Int Immunol 2011;23:637-645.

71. Huai $W$, Zhao R, Song $H$, et al. Aryl hydrocarbon receptor negatively regulates NLRP3 inflammasome activity by inhibiting NLRP3 transcription. Nat Commun 2014;5:4738.
72. Beamer CA, Seaver BP, Shepherd DM. Aryl hydrocarbon receptor (AhR) regulates silica-induced inflammation but not fibrosis. Toxicol Sci 2012;126:554-568.

73. Tian $\mathrm{Y}, \mathrm{Ke} \mathrm{S}$, Denison MS, et al. Ah receptor and NF-kappaB interactions, a potential mechanism for dioxin toxicity. J Biol Chem 1999;274:510-515.

74. Doucas V, Shi Y, Miyamoto S, et al. Cytoplasmic catalytic subunit of protein kinase A mediates cross-repression by NF-kappa B and the glucocorticoid receptor. Proc Natl Acad Sci USA 2000;97:11893-11898. 